\title{
Midcourse Guidance Law Based on High Target Acquisition Probability Considering Angular Constraint and Line-of-Sight Angle Rate Control
}

\author{
Xiao Liu, ${ }^{1}$ Shengjing Tang, ${ }^{1}$ Jie Guo, ${ }^{1}$ Yuhang Yun, ${ }^{1}$ and Zhe Chen ${ }^{2}$ \\ ${ }^{1}$ Key Laboratory of Dynamics and Control of Flight Vehicle, Ministry of Education, School of Aerospace Engineering, \\ Beijing Institute of Technology, Beijing 100081, China \\ ${ }^{2}$ China Academy of Launch Vehicle Technology, Beijing 100076, China
}

Correspondence should be addressed to Shengjing Tang; tsj8678@126.com

Received 25 December 2015; Revised 8 May 2016; Accepted 26 May 2016

Academic Editor: Paul Williams

Copyright (C) 2016 Xiao Liu et al. This is an open access article distributed under the Creative Commons Attribution License, which permits unrestricted use, distribution, and reproduction in any medium, provided the original work is properly cited.

\begin{abstract}
Random disturbance factors would lead to the variation of target acquisition point during the long distance flight. To acquire a high target acquisition probability and improve the impact precision, missiles should be guided to an appropriate target acquisition position with certain attitude angles and line-of-sight (LOS) angle rate. This paper has presented a new midcourse guidance law considering the influences of random disturbances, detection distance restraint, and target acquisition probability with Monte Carlo simulation. Detailed analyses of the impact points on the ground and the random distribution of the target acquisition position in the 3D space are given to get the appropriate attitude angles and the end position for the midcourse guidance. Then, a new formulation biased proportional navigation (BPN) guidance law with angular constraint and LOS angle rate control has been derived to ensure the tracking ability when attacking the maneuvering target. Numerical simulations demonstrates that, compared with the proportional navigation guidance (PNG) law and the near-optimal spatial midcourse guidance (NSMG) law, BPN guidance law demonstrates satisfactory performances and can meet both the midcourse terminal angular constraint and the LOS angle rate requirement.
\end{abstract}

\section{Introduction}

As a result of random disturbance factors, the missile will deviate from the ideal trajectory during the flight. The target acquisition point, where the seeker begins to work, changes in the space with distribution modes because of the stochastic disturbances. As a consequence, the seeker may fail to observe the target accurately and the midcourse guidance is needed. U.S. Army Research Laboratory conducted a series of firings at its large-caliber indoor spark range. The objective was to measure the trajectory deflection [1]. A unique guidance and control strategy that enables precision and trajectory shaping with reduced sensor and actuator needs was also introduced $[2,3]$.

One of the primary objectives of midcourse guidance is to guide the missile to an appropriate position so that the terminal impact can subsequently be very effective on attacking the target [4]. Numerous midcourse missile guidance schemes have been proposed in the literatures. Cheng and Gupta [5] considered a midcourse guidance of beyondvisual-range air-to-air tactical missiles, of which midcourse guidance formulation minimizes flight time subject to a terminal intercept condition. The paper applied the singular perturbation techniques and the engineering approximations to completely eliminate the need for solving two-point boundary value problem. Naidu and Calise [6] studied the singular perturbations and time scales in guidance and control of aerospace systems. Menon and Briggs [7] derived a near-optimal midcourse guidance law incorporating a linear combination of flight time and terminal specific energy as the performance index using singular perturbation theory. Slater and Stern [8] explained and compared several techniques 


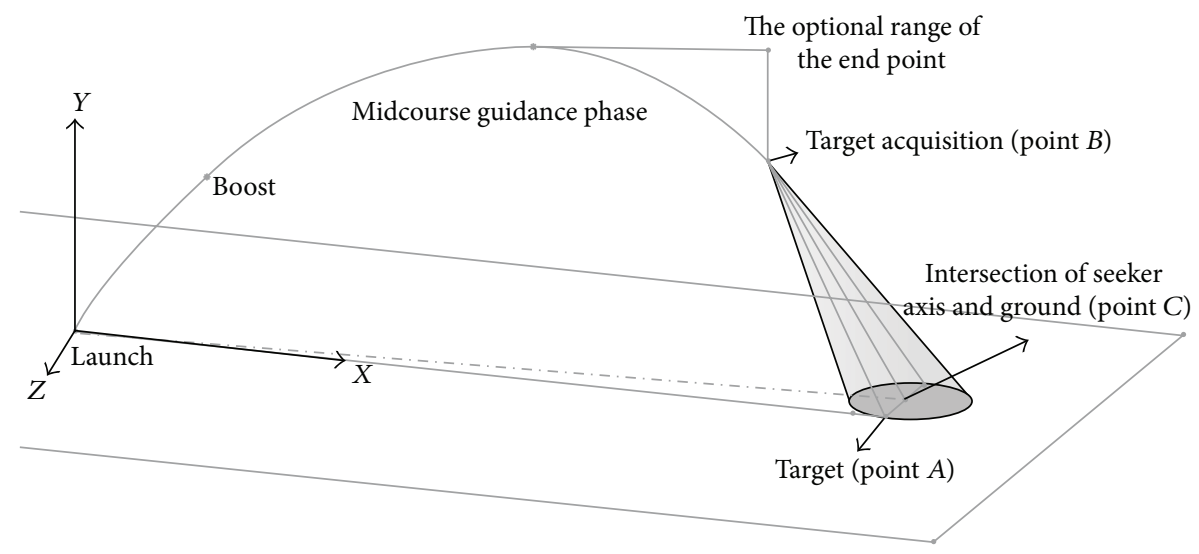

Figure 1: Phases of flight.

such as explicit, implicit, and linear guidance technique for midcourse guidance. With the help of the midcourse guidance, missiles could be guided to the proper position and start the terminal guidance after observing the target. Tournes et al. [9] proposed a higher order sliding mode guidance and control method to guide the interceptor to the predictive position. Indig et al. [10] developed a novel near-optimal spatial midcourse guidance to the predicted interception point under a terminal angular constraint. But to ensure observing the target, it also requires a low seeker view angle to get the appropriate initial condition for terminal phase. Concerning this aspect, the optimal guidance laws with terminal angular constraint could be used for the reference. Kim and Grider [11] studied the design of a suboptimal terminal guidance system for reentry vehicles with a constraint on the body attitude angle at impact. The problem is tackled within the framework of linear quadratic optimization. Bryson and Ho solved an optimal control problem for rendezvous [12]. Ryu and Cho [13] applied Bryson and Ho's result to the guidance problem for slowly moving targets. Nesline and Zarchan explored the implementations of proportional navigation guidance so that faster guidance time constants can be realized in the presence of imperfect seeker stabilization. Furthermore, it showed that LOS reconstruction achieved this goal thus enabling the guidance system to execute more accurate homing [14]. References [11-14] are based on linearized models of pursuit kinematics. So, they are unable to derive any analytic condition for fulfilling the guidance goal. In order to implement their guidance law, a time-togo estimation is also necessary. Tahk et al. [15] adopted a recursive time-to-go computation method, which is simple and straightforward to implement for any missile velocity profiles. Kim et al. [16] designed a new homing guidance law and was able to impact a target with a desired attitude angle even against a maneuvering target. Ryoo et al. [17] proposed the generalized form of the energy minimization optimal guidance laws with terminal impact angle constraint.

On one hand, the end position of the midcourse guidance influences the target acquisition probability; on the other hand it affects the terminal guidance accuracy. Papers stated above are focused on the impact points on the ground.
However, when the missile is under flight regime, preceding works do not involve the target acquisition points in the space due to the disturbance factors. Actually, not only the distribution of the target acquisition points, but also the LOS angle rate exerts definite influence on the tracking performance. As a consequence, to ensure a high target acquisition probability and improve the impact precision of terminal phase afterwards, the midcourse guidance should drive the missile to a proper position with both appropriate attitude and LOS angle rate.

In this paper, the stochastic distribution and the LOS angle rate of target acquisition position at the end of the midcourse guidance were investigated to improve the impact precision of terminal guidance. The probability ellipse and probability ellipsoid model are established. To ensure the seeker observing the target effectively, $3 \sigma$ principle is adopted (target acquisition probability is 99.7\%). Then, statistical parameters of the view angles at different positions are collected through the Monte Carlo simulation. With cubic spline interpolation method, the appropriate attitude angles and the end position for the midcourse guidance are obtained. The BPN guidance law considering angular constraint and LOS angle rate control is derived subsequently in this paper. Finally numerical simulations in 3D scenarios are carried out and validate the effectiveness of the proposed guidance law.

\section{The Target Acquisition Point and the Attitude Angle of the Midcourse Guidance}

The research object of this paper is focused on the typical tactical missile, of which the trajectory consists of three phases, namely, boost phase, midcourse phase, and terminal phase. As one of the necessary conditions, missiles must be accurately launched over the target area. Figure 1 demonstrates the distinct periods of flight, where points $A, B$, and $C$ denote the target position, the target acquisition point, and the intersection of seeker axis and the ground, respectively.

The target acquisition position should be in a definite range, within which the distance to the target is smaller than the seeker's maximum detection distance. If the seeker operates too early or late, it might fail to observe the target. 


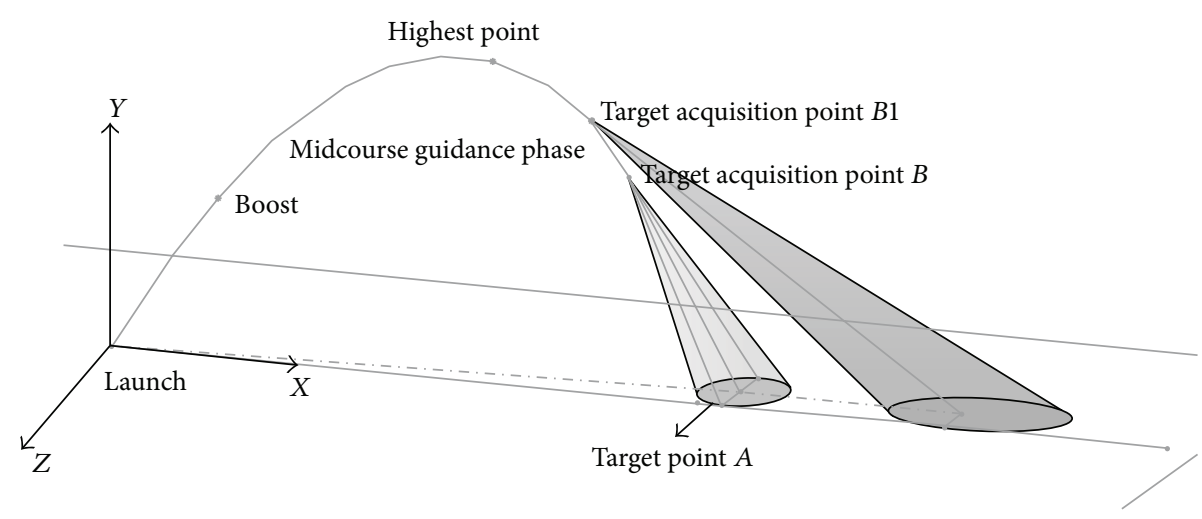

FIGURE 2: Different position of the target acquisition point.

As shown in Figure 2, if the seeker begins to work very early such as point $B 1$, the observing area is not aimed at the target area. At this moment, the view angle is considerably large. On the contrary if the seeker operates too late, although the seeker axis is aimed at the target area, the observing area is too small to cover the target. Therefore it is worthwhile to specify the appropriate target acquisition position.

\subsection{Mathematical Description of Random Distribution.} Firstly, some fundamental assumptions are introduced as follows.

(A1) It is assumed that the seeker has no mounting angle and the seeker axis coincides with the missile body axis.

(A2) The velocity of the moving target is known and constant.

(A3) The earth is regarded as flat and stationary in inertial space; thus the rotation velocity is neglected. And Newton's laws of motion are valid.

(A4) The acceleration of gravity does not change with the flight altitude.

(A5) The missile is symmetrical. And the distribution of inner masses is symmetrical for the airplane; therefore the product of inertia $I_{x z}=I_{z x}=0, I_{y z}=I_{z y}=0$.

Then the target point $A$ is assumed to be the impact point obtained from the free-flight ideal trajectory simulation. Point $B$ is obtained from the trajectory simulation and point $C$ is considered to be the intersection of the line from point $B$ along to the missile body axis and the ground. According to the definition of the line in the space,

$$
\frac{x-x_{B}}{m}=\frac{y-y_{B}}{n}=\frac{z-z_{B}}{p},
$$

where $\left(x_{B}, y_{B}, z_{B}\right)$ indicates the target acquisitions position (point $B)$ and $(m, n, p)$ denotes the nonzero vector parallel to the line. According to the coordinate transformation, the flight path angle $\theta$ and the yaw angle $\psi$ can be expressed as

$$
\begin{aligned}
& m=\cos \theta \cos \psi, \\
& n=\sin \theta, \\
& p=-\cos \theta \sin \psi .
\end{aligned}
$$

Through the trajectory simulation, point $B$ is obtained. Let $y=0$; the intersection of seeker axis and ground (point $C$ ) is calculated as

$$
\begin{aligned}
& x=\frac{x_{B} \sin \theta-y_{B} \cos \theta \cos \psi}{\sin \theta}, \\
& y=0, \\
& z=\frac{y_{B} \cos \theta \sin \psi+z_{B} \sin \theta}{\sin \theta} .
\end{aligned}
$$

Then the half-apex angle of the cone $\angle A B C$ can be defined according to the cosine theorem. Furthermore, with Monte Carlo simulation run for $n$ times we are able to calculate the mean value $(\mu)$ and standard deviation $(\sigma)$ of the view angles, as shown

$$
\begin{aligned}
\mu & =\frac{1}{n}\left(\sum_{i=1}^{n} \angle A B C_{i}\right), \\
\sigma & =\sqrt{\frac{1}{n-1} \sum_{i=1}^{n}\left((\angle A B C)_{i}-\mu\right)^{2}} .
\end{aligned}
$$

Each impact point on the ground can be described by two-dimensional random variables while the target acquisition points in the space can be described by threedimensional random variables similarly. It is assumed that there is no systematic error. The impact points will be distributed on both sides of the $x$ - $z$ axis symmetrically and the center of the distribution is located at the origin. As shown in Figure 3, $X, Z$ stand for the random variables of impact points in horizontal and longitudinal coordinate separately. However, if the systematic errors exist, the center 


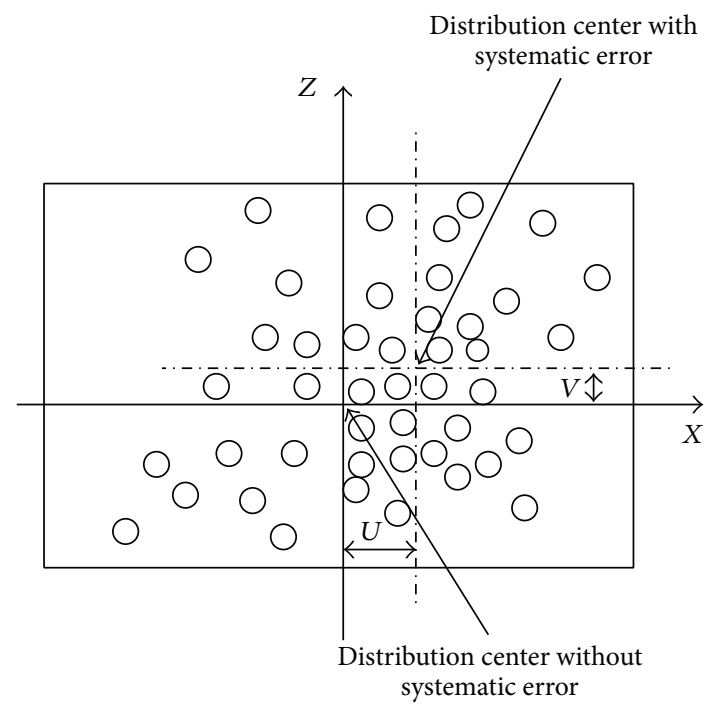

FIGURE 3: Distribution of the impact points.

of the distribution does no longer coincide with the aiming center and there would be the error $U, V$, which denotes the systematic error of impact points at $x, z$ direction.

Suppose $\bar{x}, \bar{z}$ stand for the mathematical expectation of $X, Z$, respectively. We have

$$
\begin{aligned}
X & =U+\bar{x} \\
Z & =V+\bar{z} \\
U & =X-\bar{x} \\
V & =Z-\bar{z}
\end{aligned}
$$

The two-dimensional random variables conform to the normal distribution. With the probability theory, we get the mathematical description:

$$
\begin{aligned}
& f(x, z)=\frac{1}{2 \pi \sigma_{x} \sigma_{z} \sqrt{1-r^{2}}} \\
& \cdot \exp \left\{-\frac{1}{2\left(1-r^{2}\right)}\left[\left(\frac{x-\bar{x}}{\sigma_{x}}\right)^{2}-2 r \frac{(x-\bar{x})(z-\bar{z})}{\sigma_{x} \sigma_{z}}\right.\right. \\
& \left.\left.+\left(\frac{z-\bar{z}}{\sigma_{z}}\right)^{2}\right]\right\} \\
& \sigma_{x}=\sqrt{\frac{\sum_{i=1}^{n}\left(x_{i}-\bar{x}\right)^{2}}{n-1}}, \\
& \sigma_{z}=\sqrt{\frac{\sum_{i=1}^{n}\left(z_{i}-\bar{z}\right)^{2}}{n-1}},
\end{aligned}
$$

where $r$ is the correlation coefficient of $X, Z$. In (7)-(8), $\sigma_{x}, \sigma_{z}$ are standard deviations of $X, Z$.
According to the two-dimensional normal distribution law, if $X, Z$ are independent of each other, we have

$$
\begin{aligned}
& r=0, \\
& f(x, z) \\
& \quad=\frac{1}{2 \pi \sigma_{x} \sigma_{z}} \exp \left\{-\frac{1}{2}\left(\frac{x-\bar{x}}{\sigma_{x}}\right)^{2}-\frac{1}{2}\left(\frac{z-\bar{z}}{\sigma_{z}}\right)^{2}\right\} .
\end{aligned}
$$

In the absence of systematic error, the distribution center coincides with the aiming center, which yields

$$
f(x, z)=\frac{1}{2 \pi \sigma_{x} \sigma_{z}} \exp \left(-\frac{x^{2}}{2 \sigma_{x}}-\frac{z^{2}}{2 \sigma_{z}}\right) .
$$

$E_{x}$ is defined as the probability error of $X$. Also $E_{x}>0$, and

$$
P\left(|X-\bar{x}| \leq E_{x}\right)=\frac{1}{2} .
$$

From the standard normal distribution

$$
\begin{gathered}
P\left(|X-\bar{x}| \leq E_{x}\right)=2 \Phi\left(\frac{E_{x}}{\sigma_{x}}\right)-1=\frac{1}{2}, \\
\Phi\left(\frac{E_{x}}{\sigma_{x}}\right)=\frac{(1 / 2+1)}{2}=0.75 .
\end{gathered}
$$

By means of standard normal function table, we get $\Phi\left(E_{x} /\right.$ $\left.\sigma_{x}\right)=0.75 \rightarrow E_{x} / \sigma_{x}=0.675$.

Let

$$
\begin{gathered}
E_{x}=\sqrt{2} \rho \sigma_{x}=0.675 \sigma_{x}, \\
\rho=\frac{0.675}{\sqrt{2}} \approx 0.4773,
\end{gathered}
$$

where $\rho$ is a conversion coefficient between the probability error and standard deviation.

Substituting (14) into (10) yields

$$
\begin{aligned}
& f(x, z) \\
& \quad=\frac{\rho^{2}}{\pi E_{x} E_{z}} \exp \left\{-\rho^{2}\left[\frac{(x-\bar{x})^{2}}{E_{x}^{2}}-\frac{(z-\bar{z})^{2}}{E_{z}^{2}}\right]\right\} .
\end{aligned}
$$

The intersecting line between surface $Y=f(x, z)$ and the plane $Y=C$ is depicted as

$$
\begin{aligned}
C & =f(x, z) \\
& =\frac{\rho^{2}}{\pi E_{x} E_{z}} \exp \left\{-\rho^{2}\left[\frac{(x-\bar{x})^{2}}{E_{x}^{2}}-\frac{(z-\bar{z})^{2}}{E_{z}^{2}}\right]\right\} .
\end{aligned}
$$

Take the logarithm of (17)

$$
\frac{(x-\bar{x})^{2}}{E_{x}^{2}}-\frac{(z-\bar{z})^{2}}{E_{z}^{2}}=\frac{1}{\rho^{2}} \ln \frac{\rho^{2}}{\pi E_{x} E_{z} C} .
$$




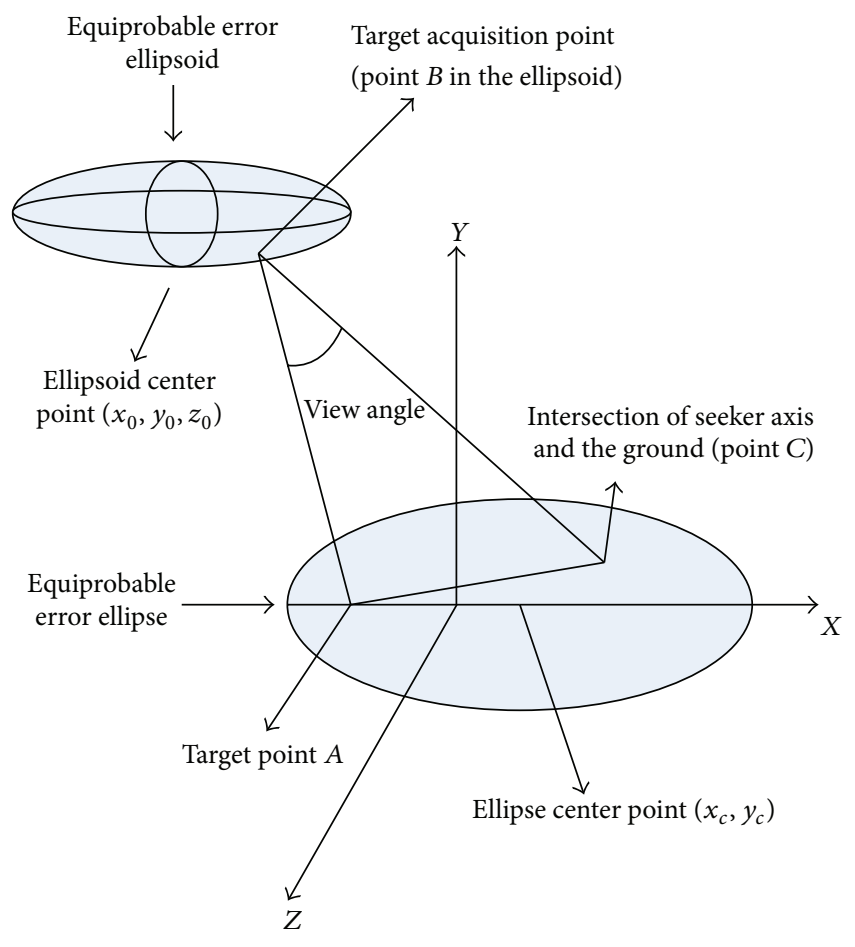

FIGURE 4: Equiprobable error ellipsoid and ellipse.

Let

$$
K^{2}=\frac{1}{\rho^{2}} \ln \frac{\rho^{2}}{\pi E_{x} E_{z} C} .
$$

Therefore, the intersecting line follows:

$$
\frac{(x-\bar{x})^{2}}{\left(K E_{x}\right)^{2}}+\frac{(z-\bar{z})^{2}}{\left(K E_{z}\right)^{2}}=1 .
$$

This ellipse describes the probability distribution of the random variables. As the probability density on the distribution ellipse is equal, it is called the equiprobable error ellipse as well. Similarly we have the 3-dimensional equiprobable error ellipsoid:

$$
\frac{(x-\bar{x})^{2}}{\left(K E_{x}\right)^{2}}+\frac{(y-\bar{y})^{2}}{\left(K E_{y}\right)^{2}}+\frac{(z-\bar{z})^{2}}{\left(K E_{z}\right)^{2}}=1 .
$$

Figure 4 demonstrates the relative position of acquisition model.

To ensure the seeker observing the target effectively, we adopt the $3 \sigma$ principle, which indicates the confidence interval of the view angles distribution is $(\mu-3 \sigma, \mu+3 \sigma)$. The requirement is that the maximum value of the confidence interval should be smaller than that of the seeker's view angle. That is, if $\mu+3 \sigma$ is larger than the maximum value of the seeker's view angle, it cannot meet the requirement and the target acquisition probability will not exceed $99.7 \%$. Next we need to calculate the value of view angles at different position, clarify the view angle distribution, and find the minimum mean value by using the cubic spline interpolation method, which has been specified in [18].

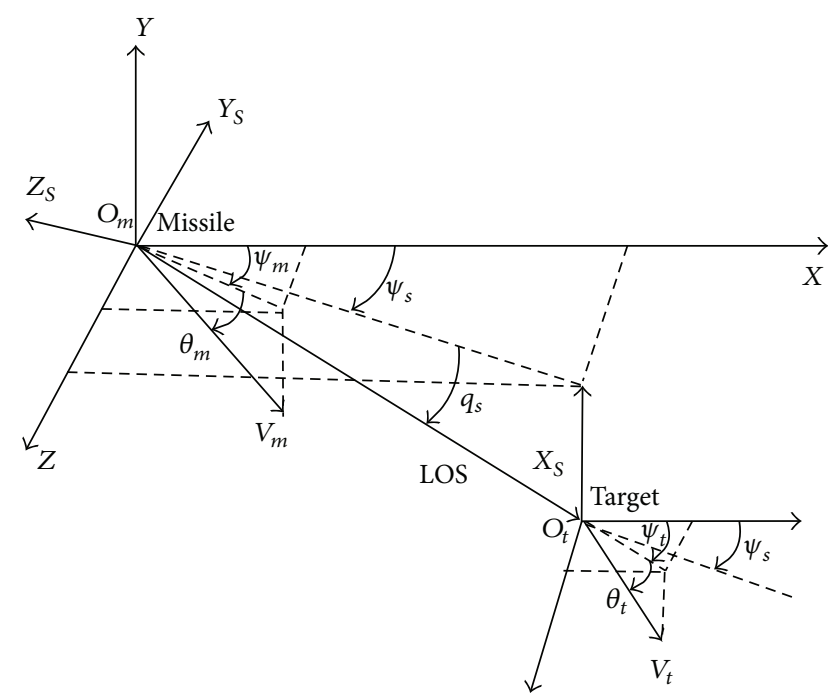

FIgURE 5: Three-dimensional pursuit geometry.

\section{Midcourse Guidance Model Construction}

Figure 5 exhibits the three-dimensional engagement problem. $M, T$ stand for the position of missile and target. The relative movement equations are written as

$$
\begin{aligned}
\dot{R} & =V_{t}\left[\cos \theta_{t} \cos \left(\psi_{t}-\psi_{s}\right) \cos q_{s}+\sin \theta_{t} \sin q_{s}\right] \\
& -V_{m}\left[\cos \theta_{m} \cos \left(\psi_{m}-\psi_{s}\right) \cos q_{s}+\sin \theta_{m} \sin q_{s}\right]
\end{aligned}
$$

$R \dot{q}_{s}$

$$
\begin{aligned}
& =V_{m}\left[\cos \theta_{m} \cos \left(\psi_{m}-\psi_{s}\right) \sin q_{s}-\sin \theta_{m} \cos q_{s}\right] \\
& -V_{t}\left[\cos \theta_{t} \cos \left(\psi_{t}-\psi_{s}\right) \sin q_{s}-\sin \theta_{t} \sin q_{s}\right] \\
R \dot{\psi}_{s} \cos q_{s}=V_{t} \cos \theta_{t} \sin \left(\psi_{t}-\psi_{s}\right) & -V_{m} \cos \theta_{m} \sin \left(\psi_{m}-\psi_{s}\right)
\end{aligned}
$$

where $R$ is the relative distance from missile to target and $q_{s}$ and $\psi_{s}$ are LOS angles in the pitching plane and swerve plane, respectively. Subscripts $m$ and $t$ represent the parameters for missile and target. The rest, $V, \theta, \psi$, are velocity, flight path angle, and flight path deflection angle, respectively; threedimensional engagement scenario can be decoupled into pitching plane and swerve plane. Figure 6 shows the pursuit geometry in the pitching plane, where $\sigma, \sigma_{t}$ are the flight path angle of missile and target. $\eta, \eta_{t}$ indicate the angle between LOS and the velocity vector of missile and target. have

Considering the vertical plane, where $\sigma=\theta_{m}, \sigma_{t}=\theta_{t}$. We

$$
\begin{aligned}
\dot{R} & =V_{t} \cos \left(q_{s}-\theta_{t}\right)-V_{m} \cos \left(q_{s}-\theta_{m}\right), \\
R \dot{q} & =-V_{t} \sin \left(q_{s}-\theta_{t}\right)+V_{m} \sin \left(q_{s}-\theta_{m}\right) .
\end{aligned}
$$




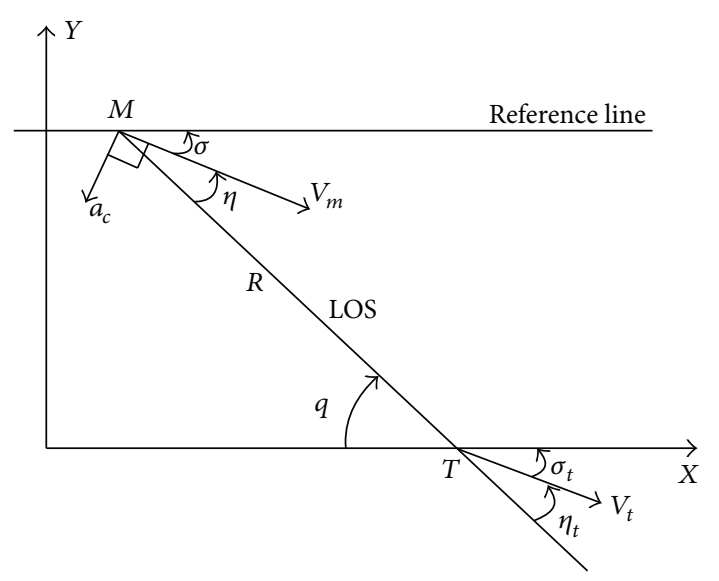

FIGURE 6: LOS planar pursuit geometry.

Differentiating (24) and utilizing (23), we get the derivative of LOS angle rate:

$$
\begin{aligned}
R \ddot{q}_{s}+2 \dot{R} \dot{q}_{s}= & -V_{m} \dot{\theta}_{m} \cos \left(\theta_{m}-q_{s}\right) \\
& +V_{t} \dot{\theta}_{t} \cos \left(\theta_{t}-q_{s}\right), \\
\ddot{q}_{s}= & -\frac{2 \dot{R}}{R} \dot{q}_{s}-\frac{1}{R} A_{m q}+\frac{1}{R} A_{t q}, \\
A_{m q}= & V_{m} \dot{\theta}_{m} \cos \left(\theta_{m}-q_{s}\right), \\
A_{t q}= & V_{t} \dot{\theta}_{t} \cos \left(\theta_{t}-q_{s}\right),
\end{aligned}
$$

where $A_{m q}$ and $A_{t q}$ are the normal accelerations of missile and target which are perpendicular to LOS in the pitching plane, respectively.

Similarly, the result in swerve plane is given as

$$
\begin{aligned}
\ddot{\psi}_{s} & =-\frac{2 \dot{R}_{H}}{R_{H}} \dot{\psi}_{s}+\frac{1}{R_{H}} A_{m \psi}-\frac{1}{R_{H}} A_{t \psi}, \\
R_{H} & =R \cos q_{s},
\end{aligned}
$$

where $A_{m \psi}$ and $A_{t \psi}$ are the swerve plane accelerations of missile and target.

\section{New Formulation of BPN Midcourse Guidance Law Design}

In the design of midcourse guidance, except for zero miss distance requirement, the attitude angle at the target acquisition position is much more crucial. That is to say, $\vartheta_{B}$ should be an appropriate value at the end position of the midcourse phase, so that the seeker can observe the target accurately. Since the attitude angle and the LOS angle on the collision course have one-to-one correspondence, in the following part we neglect the angle of attack and assume $q_{B} \approx \theta_{B} \approx \vartheta_{B}[19]$.

However, if the target keeps maneuvering, special attention to LOS angle rate at the target acquisition point needs to be paid. Both the midcourse guidance laws in Figures 7 and 8 have the angular constraint requirement. Figure 7

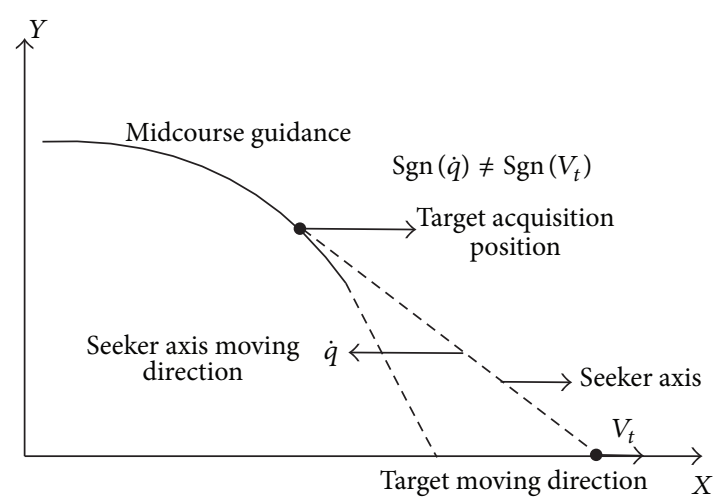

FIGURE 7: Midcourse guidance law without LOS angle rate control.

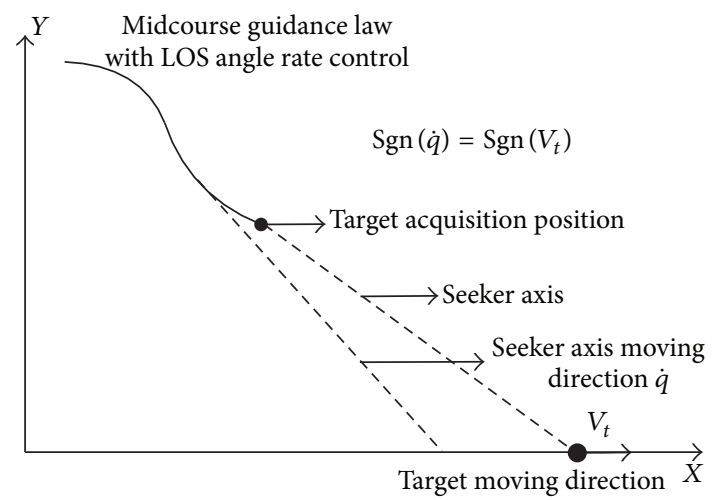

FIGURE 8: Midcourse guidance law with LOS angle rate control.

illustrates the midcourse guidance law without LOS angle rate control. If the moving direction of the seeker axis is different to the target moving direction, the condition is not effective for target tracking. The view angle would be increased and the seeker would lose the target at the terminal guidance probably. On the contrary, Figure 8 embodies the control of the LOS angle rate. The moving direction of the seeker axis is in accord with the target moving direction. This meets the requirement of appropriate LOS angle rate, consequently providing the missile with a better initial condition for terminal phase.

Suppose the velocity of the moving target is $V_{t}=\left(V_{t x}\right.$, $0,0)(\mathrm{m} / \mathrm{s})$. In the target acquisition point, the required LOS angle rate is

$$
\begin{aligned}
& \dot{q}_{r} \\
& =\frac{\arctan \left(y_{B} /\left(x_{A}-x_{B}\right)\right)-\arctan \left(y_{B} /\left(x_{A}+V_{t x} \Delta t-x_{B}\right)\right)}{\Delta t} .
\end{aligned}
$$

So far, the requirements at the end of the midcourse guidance are summarized as follows: the missile has to reach the desired point $\left(x_{f}, y_{f}, z_{f}\right)=\left(x_{B}, y_{B}, z_{B}\right)$; at the same time, the missile is desired to have a certain attitude angle $\vartheta_{B}$ and the LOS angle rate should be $\dot{q}_{r}$. These conditions ensure the missile tracks the maneuvering target accurately. 


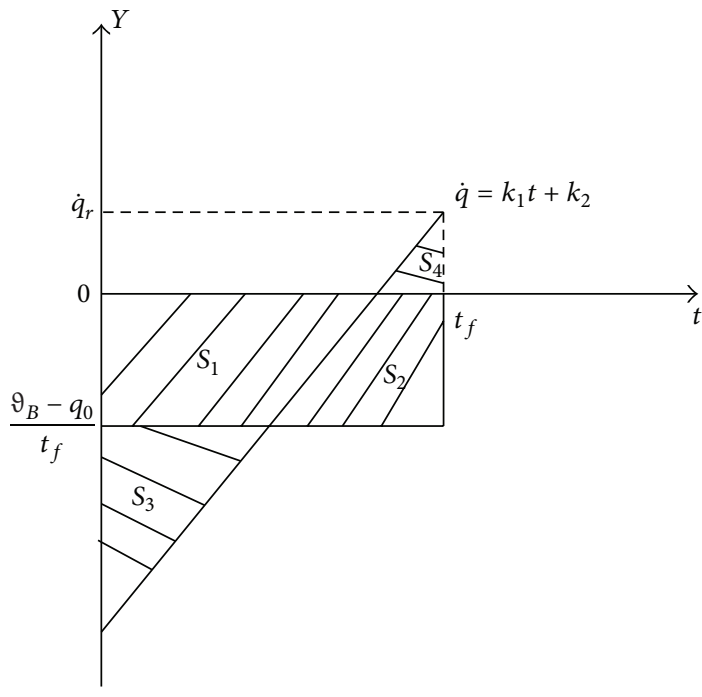

FIGURE 9: LOS angle rate equation designed by the first-order equation.

The NSMG [10] law can guide the missile start from $\left(x_{0}\right.$, $\left.y_{0}, z_{0}\right)$ to $\left(x_{B}, y_{B}, z_{B}\right)$ with angular constraint. But it cannot control the LOS angle rate. To conclude, the guidance law to be derived should satisfies the following: (1) angular constraint; that is, when $t=t_{f}$, the missile gets to a certain attitude angle $q_{f}=\vartheta_{B}$; (2) LOS angle rate control; namely, the LOS angle rate $\dot{q}$ at $t=t_{f}$ equals $\dot{q}_{r}$ at the end of the midcourse guidance.

As the midcourse phase starts from point $\left(x_{0}, y_{0}, z_{0}\right)$ and ends at the desired point $B\left(x_{B}, y_{B}, z_{B}\right)$, we have

$$
\begin{aligned}
q_{0} & =-\arctan \left(\frac{y_{0}-y_{B}}{x_{B}-x_{0}}\right), \\
q_{0}+\int_{0}^{t_{f}}(\dot{q}) d t & =q_{f}, \\
\psi_{0} & =-\arctan \left(\frac{z_{0}-z_{B}}{x_{B}-x_{0}}\right), \\
\psi_{0}+\int_{0}^{t_{f}}(\dot{q}) d t & =\psi_{f},
\end{aligned}
$$

where $t_{f}=\left.t_{\mathrm{go}}\right|_{\left(x_{0}, y_{0}, z_{0}\right)} ^{\left(x_{f}, y_{f}, z_{f}\right)}$. According to [20] the guidance law could be written as polynomial form. Here we first assumed the new guidance law's LOS angle rate varies as the first-order form $\dot{q}=k_{1} t+k_{2}$. As stated before, the missile should satisfy the attitude constraint; that is, $q_{f}=\vartheta_{B}$; in mathematics, the integral can be expressed by calculating the area. As shown in Figure 9, then we have

$$
\int_{0}^{t_{f}}(\dot{q}) d t=\vartheta_{B}-q_{0}=S_{1}+S_{2} .
$$

The new guidance law should satisfy $S_{1}+S_{2}=S_{1}+S_{3}+$ $S_{4}$. Next considering the LOS angle rate at the end of the

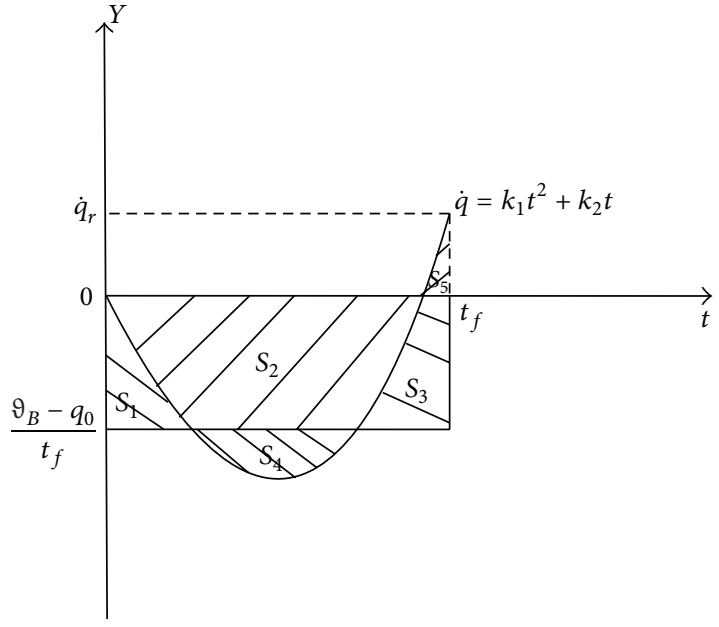

FIGURE 10: LOS angle rate equation designed by the second-order equation.

midcourse guidance, we get $\left.\dot{q}\right|_{t=t_{f}}=k_{1} t_{f}+k_{2}=\dot{q}_{r}$. To conclude, the first-order equation of $\dot{q}$ conforms to

$$
\begin{gathered}
\int_{0}^{t_{f}}\left(k_{1} t+k_{2}\right) d t=\vartheta_{B}-q_{0}, \\
k_{1} t_{f}+k_{2}=\dot{q}_{r} .
\end{gathered}
$$

When $k_{1}, k_{2}$ are solved from (30), we get $\dot{q}$ of new midcourse guidance law

$$
\frac{d q}{d t}=\frac{V_{m} \sin \eta-V_{t} \sin \eta_{t}}{R}=k_{1} t+k_{2} .
$$

We have

$$
\begin{aligned}
\sin \eta & =\sin (q-\sigma)=\frac{R\left(k_{1} t+k_{2}\right)+V_{t} \sin \eta_{t}}{V_{m}}, \\
\sigma & =q-\arcsin \left(\frac{R\left(k_{1} t+k_{2}\right)+V_{t} \sin \eta_{t}}{V_{m}}\right) .
\end{aligned}
$$

For the first-order equation $\dot{q}=k_{1} t+k_{2}$, we noticed that the initial value of $\dot{q}$ designed by the first-order equation method is considerably large. The absolute value is $\left|\dot{q}_{t=0}\right|=$ $\left|k_{2}\right|$. With the velocity and the initial relative distance restrictions, $\dot{q}$ cannot exceed the kinematics value. For example, if $V_{t}=0, \sin \eta=1, \eta_{t}=0, \dot{q}$ gets its maximum value $\dot{q}_{\max }=$ $V_{m} / R$. It means the value of $\left|k_{2}\right|$ cannot exceed $\dot{q}_{\max }$. If $\dot{q}_{\max }<$ $\left|k_{2}\right|$, the missile cannot follow the kinematics required by the new guidance law. To solve this problem, the new midcourse guidance law is improved with the second-order equation.

Assume the LOS angle rate varies as the second-order equation $\dot{q}=k_{1} t^{2}+k_{2} t$. As shown in Figure 10, the requirements are as follows: (1) when $t=t_{f}$, the missile gets to a certain attitude angle. That is, $q_{f}=\mathcal{\vartheta}_{B}$, which means $\int_{0}^{t_{f}}(\dot{q}) d t=$ $\vartheta_{B}-q_{0}=S_{1}+S_{2}+S_{3}$. So the improved guidance law must fulfill $S_{1}+S_{2}+S_{3}=S_{2}+S_{4}+S_{5}$. (2) the LOS angle rate satisfies $\left.\dot{q}\right|_{t=t_{f}}=\dot{q}_{r}$. 
According to the above requirements, the second-order equation $\dot{q}=k_{1} t^{2}+k_{2} t$ should meet

$$
\begin{gathered}
\int_{0}^{t_{f}}\left(k_{1} t^{2}+k_{2} t\right) d t=\vartheta_{B}-q_{0}, \\
k_{1}\left(t_{f}\right)^{2}+k_{2} t_{f}=\dot{q}_{r} .
\end{gathered}
$$

When $k_{1}, k_{2}$ are solved from (33), we get $\dot{q}$ of the improved midcourse guidance law

$$
\frac{d q}{d t}=\frac{V_{m} \sin \eta-V_{t} \sin \eta_{t}}{R}=k_{1} t^{2}+k_{2} t
$$

We have

$$
\begin{aligned}
\sin \eta & =\sin (q-\sigma)=\frac{R\left(k_{1} t^{2}+k_{2} t\right)+V_{t} \sin \eta_{t}}{V_{m}}, \\
\sigma & =q-\arcsin \left(\frac{R\left(k_{1} t^{2}+k_{2} t\right)+V_{t} \sin \eta_{t}}{V_{m}}\right)
\end{aligned}
$$

and its time derivative

$$
\dot{\sigma}=\dot{q}-\left(\arcsin \left(\frac{R\left(k_{1} t^{2}+k_{2} t\right)+V_{t} \sin \eta_{t}}{V_{m}}\right)\right)^{\prime} .
$$

It is assumed that the target velocity is constant:

$$
\begin{aligned}
\dot{\sigma}= & \dot{q}-\frac{1}{\sqrt{1-\left(\left(R\left(k_{1} t^{2}+k_{2} t\right)+V_{t} \sin \eta_{t}\right) / V_{m}\right)^{2}}} \\
& \cdot \frac{1}{V_{m}}\left[\left(2 k_{1} t+k_{2}\right) R+\left(k_{1} t^{2}+k_{2} t\right) \dot{R}\right] .
\end{aligned}
$$

The general form of BPN is

$$
\dot{\sigma}=N \dot{q}+b
$$

where $N$ is the navigation gain and $b$ is the bias.

$\begin{array}{ccc}\text { When } N=1, b & =1 / \\ \sqrt{1-\left(\left(R\left(k_{1} t^{2}+k_{2} t\right)+V_{t} \sin \eta_{t}\right) / V_{m}\right)^{2}} \cdot\left(1 / V_{m}\right)\left[\left(2 k_{1} t+k_{2}\right) R\right.\end{array}$ $\left.+\left(k_{1} t^{2}+k_{2} t\right) \dot{R}\right]$, it is the second-order form of the proposed midcourse guidance law.

The general form of the proposed midcourse guidance law can be written as follows.

In pitching plane,

$$
\begin{aligned}
a_{c 1} & =V_{\mathrm{mp}}[\dot{q} \\
& -\frac{1}{\sqrt{1-\left(\left(R\left(k_{1} t^{2}+k_{2} t\right)+V_{t} \sin \eta_{t}\right) / V_{m}\right)^{2}}} \\
& \left.\cdot \frac{1}{V_{m}}\left[\left(2 k_{1} t+k_{2}\right) R+\left(k_{1} t^{2}+k_{2} t\right) \dot{R}\right]\right],
\end{aligned}
$$

where $V_{\mathrm{mp}}$ is the projection of missile velocity in pitching plane.

Similarly, in swerve plane

$$
\begin{aligned}
a_{c 2} & =-V_{\mathrm{ms}}\left[\dot{\psi}_{s}\right. \\
& -\frac{1}{\sqrt{1-\left(\left(R\left(k_{1} t^{2}+k_{2} t\right)+V_{t} \sin \eta_{t}\right) / V_{m}\right)^{2}}} \\
& \left.\cdot \frac{1}{V_{m}}\left[\left(2 k_{1} t+k_{2}\right) R+\left(k_{1} t^{2}+k_{2} t\right) \dot{R}\right]\right] \cos \theta_{m},
\end{aligned}
$$

where $V_{\mathrm{ms}}$ is the projection of missile velocity in swerve plane.

Both the first-order and the second-order form of the proposed midcourse guidance law belong to BPN guidance law. For the second-order equation $\dot{q}=k_{1} t^{2}+k_{2} t$, the initial value of $\dot{q}$ is rather small. The absolute value is $\left|\dot{q}_{t=0}\right|=0$ and the missile is able to follow the guidance command.

\section{Six-Degree-of-Freedom Monte Carlo Simulation}

Considering the effect of disturbances, a 6-DOF model [21] of the system is established as

$$
\begin{aligned}
& m \frac{d V_{m}}{d t}=P \cos \alpha_{W}^{*} \cos \beta_{W}^{*}-X_{1}-m g \sin \theta \\
& m V_{m} \frac{d \theta}{d t} \\
& =P\left(\sin \alpha_{W}^{*} \cos \gamma_{V W}^{*}+\cos \alpha_{W}^{*} \sin \beta_{W}^{*} \sin \gamma_{V W}^{*}\right) \\
& \quad+Y_{1} \cos \gamma_{V W}^{*}-Z_{1} \sin \gamma_{V W}^{*}-m g \cos \theta, \\
& m V_{m} \cos \theta \frac{d \psi_{V}}{d t} \\
& =P\left(\sin \alpha_{W}^{*} \sin \gamma_{V W}^{*}-\cos \alpha_{W}^{*} \sin \beta_{W}^{*} \cos \gamma_{V W}^{*}\right) \\
& \quad+Y_{1} \sin \gamma_{V W}^{*}+Z_{1} \cos \gamma_{V W}^{*}, \\
& J_{x} \frac{d \omega_{x}}{d t}=M_{x}-\left(J_{z}-J_{y}\right) \omega_{z} \omega_{y}, \\
& J_{y} \frac{d \omega_{y}}{d t}=M_{y}-\left(J_{x}-J_{z}\right) \omega_{x} \omega_{z}-J_{z} \omega_{z} \dot{\gamma}, \\
& J_{z} \frac{d \omega_{z}}{d t}=M_{z}-\left(J_{y}-J_{x}\right) \omega_{y} \omega_{x}+J_{y} \omega_{y} \dot{\gamma}, \\
& m_{0}-\int_{0}^{t} m_{c}(t) d t,
\end{aligned}
$$

where $P$ is the thrust; $X_{1}, Y_{1}, Z_{1}$ are the drag force, lift force, and the lateral force, respectively; $J_{x}, J_{y}, J_{z}$ illustrate the missile's moment of inertia in $x$-, $y$-, $z$-axis; $M_{x}, M_{y}, M_{z}$ are 
the moments acted on the $x$-, $y$-, $z$-axis. $\omega_{x}, \omega_{y}, \omega_{z}$ represent the rate of the pitch angle, yaw angle, and the slope angle. $m_{0}$ stands for the initial mass and $m_{c}(t)$ indicates the mass variation rate.
The relative velocity and the corresponding angle of attack and sideslip angle are given as

$$
\begin{aligned}
V_{W} & =\sqrt{\left(V_{m} \cos \theta \cos \psi_{V}-W_{x}\right)^{2}+\left(V_{m} \sin \theta-W_{y}\right)^{2}+\left(-V_{m} \cos \theta \sin \psi_{V}-W_{z}\right)^{2}}, \\
\theta_{W} & =\arctan \left(\frac{V_{m} \sin \theta-W_{y}}{\sqrt{\left(V_{m} \cos \theta \cos \psi_{V}-W_{x}\right)^{2}+\left(-V_{m} \cos \theta \sin \psi_{V}-W_{z}\right)^{2}}}\right), \\
\psi_{V W} & =\arctan \left(\frac{V_{m} \cos \theta \sin \psi_{V}+W_{z}}{V_{m} \cos \theta \cos \psi_{V}-W_{x}}\right), \\
\beta_{W}^{*} & =\arcsin \left[\cos \theta_{W} \sin \left(\psi-\psi_{V W}\right)\right], \\
\alpha_{W}^{*} & =\vartheta-\arcsin \left[\frac{\sin \theta_{W}}{\cos \beta_{W}^{*}}\right], \\
\gamma_{V W}^{*} & =\arcsin \left[\tan \beta_{W}^{*} \tan \theta_{W}\right],
\end{aligned}
$$

where $\alpha_{W}^{*}, \beta_{W}^{*}, V_{W}$ are the angle of attack, angle of sideslip, and the velocity relative to the wind respectively. $\gamma_{V W}^{*}$ is the slope angle of velocity relative to the wind.

Figure 11 showed the simulation flow diagram.

The given value of the view angle is $10^{\circ}$. The distance of the detection range is smaller than $3000 \mathrm{~m}$. The disturbance factors and their distributions are given in Table 1.

5.1. Distribution of the Target Acquisition Points. Initial muzzle velocity and flight path angle are $V_{0}=370(\mathrm{~m} / \mathrm{s}), \theta_{0}=$ $45^{\circ}$. When the distance between the target and the missile decreases to $2000 \mathrm{~m}$, the seeker begins to work. Figure 12 demonstrates the distribution of the target acquisition position after 500-times simulations.

Figure 13 shows the probability ellipsoid, where the distributed points indicate the target acquisition points. According to the $3 \sigma$ principle, the probability of the event that the ellipsoid covers the scatter points is larger than $99.7 \%$. Corresponding with the 500 impact points in the space, there are 500 scattered points on the ground. As visualized in Figure 14, these impact points on the ground could be approximately covered inside an ellipse ( $3 \sigma$ principle). The length of the semimajor axis of the ellipse is three times that of $\sigma_{x}$. In the same way, the length of semiminor axis of the ellipse can be calculated.

5.2. Fixed Target Example. In this case, a nonmaneuvering target is being considered. Initial muzzle velocity and the flight path angle are $V_{0}=278 \mathrm{~m} / \mathrm{s}, \theta_{0}=45^{\circ}$. The results are listed in Table 2.

Statistic parameters like mean value and standard deviation can be calculated using the cubic spline interpolation. The results are seen in Figure 15.
As shown in Table 3, when the distance to the target is $1210 \mathrm{~m}$, the mean value and the standard deviation of the view angles are $\mu=2.58^{\circ}, \sigma=1.3^{\circ}$, respectively. Compared with other results, this position and the attitude angle can provide the minimum view angle, which can be chosen as the appropriate target acquisition point.

5.3. Moving Target Example. Assume that the velocity of the moving target is $V_{t}\left(V_{t x}, V_{t y}, V_{t z}\right)=(10,0,0)(\mathrm{m} / \mathrm{s})$. To confirm the generality of the proposed method, initial muzzle velocity and the flight path angle are different with the former occasion which are $V_{0}=370 \mathrm{~m} / \mathrm{s}, \theta_{0}=45^{\circ}$. Similar to the stationary target conditions, the simulation results are demonstrated in Figure 16.

As shown in Figure 16(d), when the moving target velocity is positive and the distance to the target is $3000 \mathrm{~m}, 3 \sigma$ confidence interval is $\left(1^{\circ}, 7.6^{\circ}\right)$, which means the maximum value of the confidence interval is smaller than that of the seeker's view angle and the moving target is still in the observing area at this moment. The confidence interval of the view angle firstly decreased and then increased when the distance between the seeker and the target decreased. When the seeker begins to work at $1250 \mathrm{~m}, 1000 \mathrm{~m}, 3 \sigma$ confidence intervals are $\left(2.2^{\circ}, 16^{\circ}\right)$ and $\left(4.7^{\circ}, 19.7^{\circ}\right)$, respectively. The maximum value of the confidence interval is out of $10^{\circ}$, indicating some points are out of the observing area. As given in Table 4, when the distance changes from $3000 \mathrm{~m}$ to $1000 \mathrm{~m}$, the pitch angle varies from $-34.3^{\circ}$ to $-51.2^{\circ}$. The yaw angle varies from $-0.014^{\circ}$ to $-0.05^{\circ}$.

Figure 17 demonstrates the target acquisition region.

Statistic parameters like mean value and standard deviation can be calculated using the cubic spline interpolation. The results are demonstrated in Figure 18. 


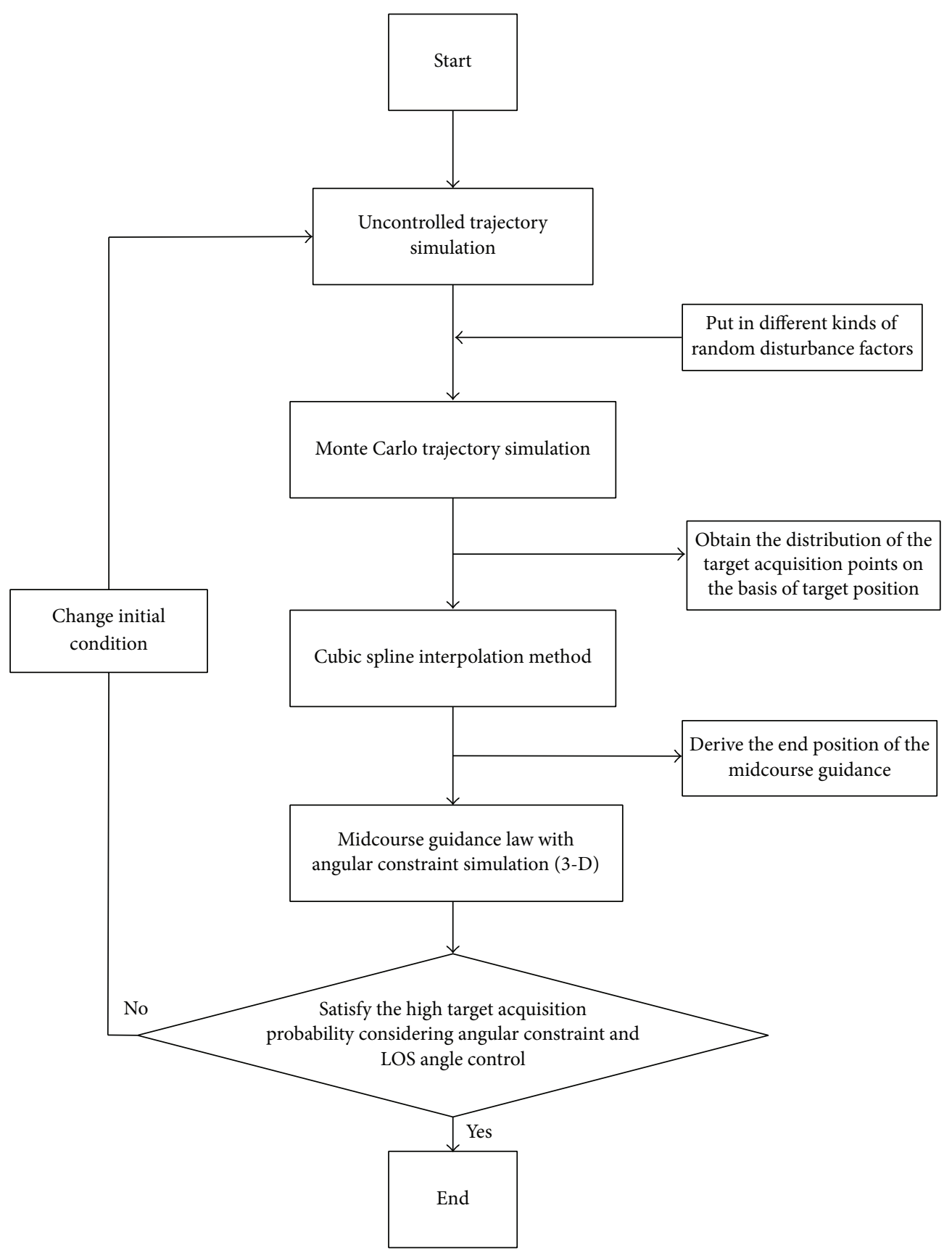

Figure 11: Simulation flow diagram.

The high target acquisition probability requirement means that the confidence interval of the view angle $(\mu-3 \sigma$, $\mu+3 \sigma)$ will not exceed $\left(0^{\circ}, 10^{\circ}\right)$. From the result in Figure 18, we know $1550 \mathrm{~m}-2600 \mathrm{~m}$ is the appropriate target acquisition range. When the distance to the target is $2260 \mathrm{~m}$, the mean value and the standard deviation of the view angles are $\mu=$ $1.5^{\circ}, \sigma=0.9^{\circ}$, respectively. Compared with other results, this position and the attitude angle can provide the minimum view angle, which is chosen as the appropriate end point of midcourse guidance. The detailed information is given in Table 5.

\section{Midcourse Guidance Simulation}

In this section, the performance with the designed midcourse guidance law is studied. Table 6 shows the conditions when attacking stationary target.

Figure 19 is the result of the midcourse flight with BPN.

Table 7 and Figure 20 are for maneuvering target occasions.

Figure 20 demonstrates both the PNG and BPN satisfy the zero midcourse miss distance. Compared with PNG, BPN can not only fulfill the impact angle constraint, but also ensure 


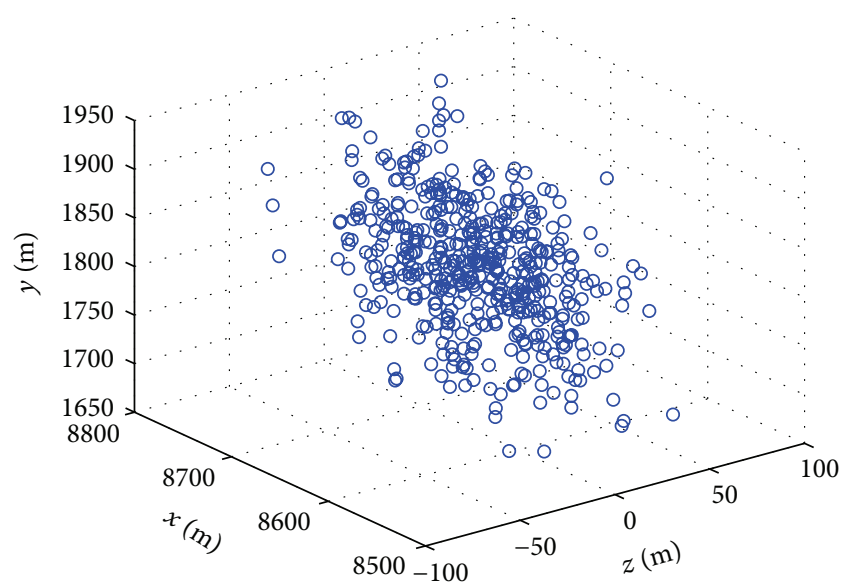

FIGURE 12: The distribution of target acquisition points.

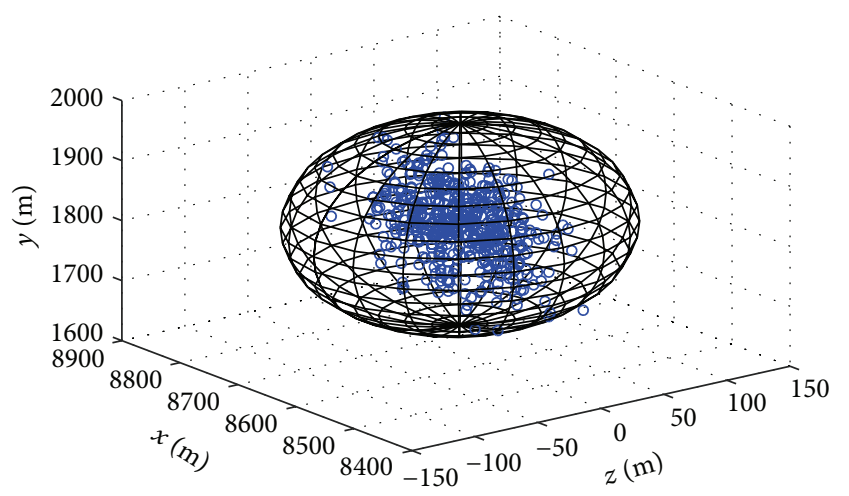

FIGURE 13: The equiprobable error ellipsoid of the target acquisition points.

TABLE 1: Disturbance factors and their distribution.

\begin{tabular}{lccc}
\hline Disturbance factor & Range & $\begin{array}{c}\text { Distribution } \\
\text { type }\end{array}$ & Unit \\
\hline $\begin{array}{l}\text { Muzzle velocity deviation } \\
\Delta V_{0}\end{array}$ & \pm 2 & $\begin{array}{c}\text { Normal } \\
\text { distribution } \\
\text { Normal } \\
\text { Initial flight path angle }\end{array}$ & $\mathrm{m} / \mathrm{s}$ \\
$\begin{array}{l}\text { deviation } \Delta \theta_{0} \\
\text { Initial flight path deflection } \\
\text { angle deviation } \Delta \psi_{v 0}\end{array}$ & \pm 0.3 & $\begin{array}{c}\text { deg } \\
\text { distribution }\end{array}$ & Normal \\
Initial angular velocity & \pm 0.5 & $\begin{array}{c}\text { distribution } \\
\text { Normal } \\
\omega_{y 0}, \omega_{z 0}\end{array}$ & $\mathrm{deg}$ \\
$\begin{array}{l}\text { Wind in } x, z \text { direction } \\
W_{x}, W_{z}\end{array}$ & \pm 5 & $\begin{array}{c}\text { Normalion } \\
\text { distribution } \\
\text { Normal }\end{array}$ & $\mathrm{m} / \mathrm{s}$ \\
Time of boost deviation $\Delta t$ & \pm 0.5 & $\begin{array}{c}\text { distribution } \\
\text { Normal }\end{array}$ & $\mathrm{s}$ \\
Thrust deviation $\Delta P$ & \pm 20 & $\begin{array}{c}\text { distribution } \\
\text { dim }\end{array}$ & $\mathrm{N}$ \\
\hline
\end{tabular}

the seeker observing the target remarkably. Furthermore, BPN can control the LOS angle rate. The LOS angle rate is $0.2(\%)$ at the end position of midcourse guidance and this would help the missile track the moving target preferably.

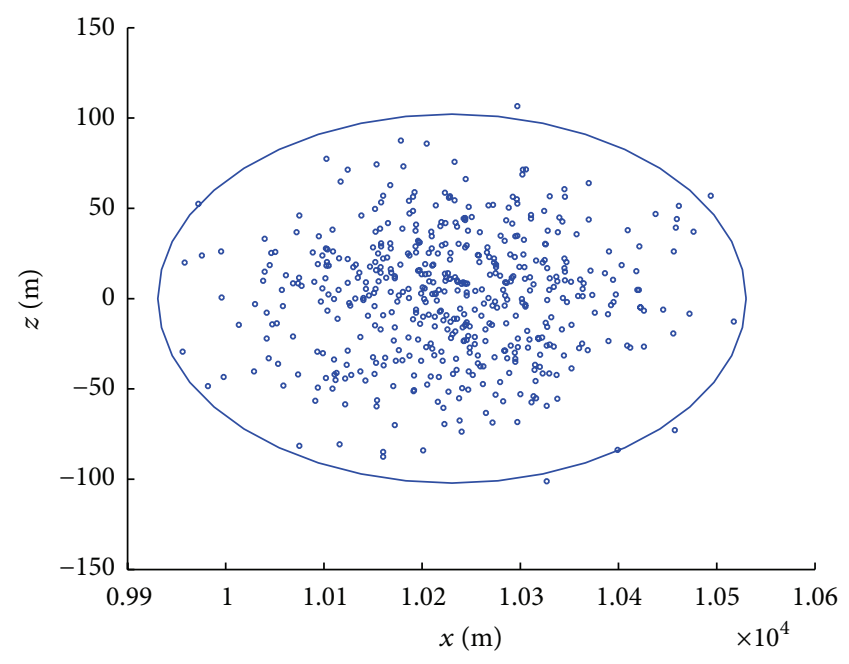

FIGURE 14: The equiprobable error ellipse of impact points.

In addition, the normal acceleration and the swerve plane acceleration are not very large.

\section{Comparison of Other Midcourse Guidance Law and BPN Guidance Law}

On this occasion, near-optimal spatial midcourse guidance law (NSMG) is adopted for comparison. The NSMG is obtained from [10]. As shown below,

$$
a_{c}=4 V_{m} \dot{\lambda}+\frac{2 V_{m}\left(\lambda-\lambda_{f}\right)}{t_{\mathrm{go}}}+a_{T},
$$

where $\lambda$ indicates the line-of-sight angle and $\lambda_{f}$ denotes the desired attitude angle at terminal target acquisition position of midcourse guidance (point $B$ ). $a_{T}$ is the target acceleration.

Table 8 gives the simulation conditions.

The simulation results are demonstrated in Figure 21.

From the results, we noticed that the trajectory of BPN is similar to that in Figure 8. It is clear that both the BPN and NSMG satisfy the zero midcourse miss distance and impact angle constraint. But new formulation BPN can control the LOS angle rate to $2(\%)$ as desired at the end position of midcourse guidance. This would help the missile track the moving target preferably.

Finally, to validate the universality of the newly derived guidance law, in the following simulations, missile trajectories are obtained by adopting BPN with various initial positions which are shown in Figure 22. Table 9 lists the parameters for simulation.

Missiles adopting BPN guidance law can hit the target with appropriate attitude angle under diverse initial positions. The results above demonstrate that the newly derived BPN guidance law can ensure the high target acquisition probability and satisfy the attitude angle constraint with appropriate LOS angle rate at the end point of midcourse guidance under different initial conditions. If the current launch conditions are out of the envelope, one might have to change initial 


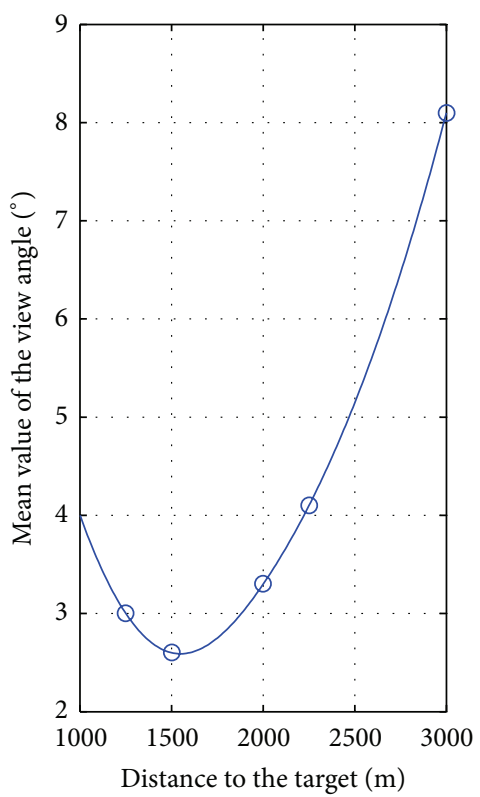

(a)

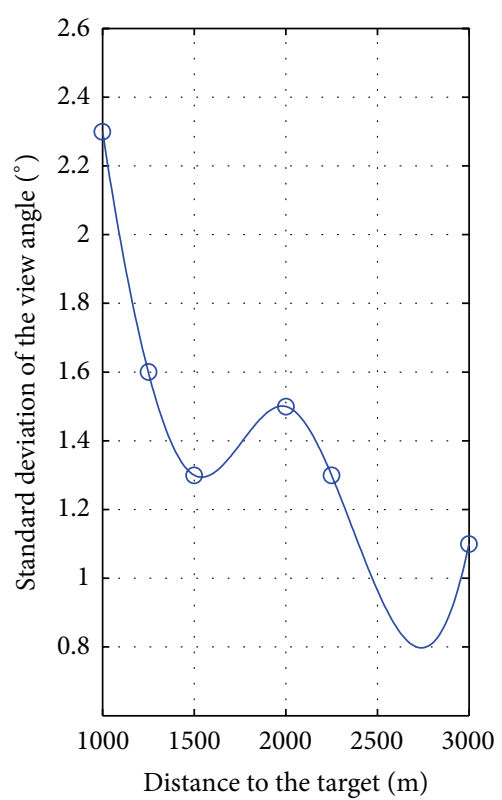

(b)

FIGURE 15: Cubic spline interpolation curve results (fixed target).

TABLE 2: View angle distribution results (fixed target).

\begin{tabular}{lcccc}
\hline $\begin{array}{l}\text { Distance to the target (target } \\
\text { acquisition point }) / \mathrm{m}\end{array}$ & $\begin{array}{c}\text { Mean value } \\
\mu /\left(^{\circ}\right)\end{array}$ & $\begin{array}{c}\text { Standard deviation } \\
\sigma /\left(^{\circ}\right)\end{array}$ & $\begin{array}{c}3 \sigma \text { confidence interval } /\left(^{\circ}\right) \\
\text { Requirement }\left(\text { smaller than } 10^{\circ}\right)\end{array}$ \\
\hline 2250 & 8.1 & 1.1 & $(4.8,11.4)$ & $\mathrm{N}$ \\
1750 & 4.1 & 1.3 & $(0,8)$ & $\mathrm{Y}$ \\
1500 & 3.3 & 1.5 & $(0,7.8)$ & $\mathrm{Y}$ \\
1250 & 2.6 & 1.3 & $(0,6.5)$ & $\mathrm{Y}$ \\
1000 & 3 & 1.6 & $(0,7.8)$ & $\mathrm{Y}$ \\
750 & 4 & 2.3 & $(0,10.9)$ & $\mathrm{N}$ \\
\hline
\end{tabular}

TABLE 3: The end point of midcourse guidance.

\begin{tabular}{lcccccc}
\hline $\begin{array}{l}\text { Distance to the } \\
\text { target } / \mathrm{m}\end{array}$ & $\begin{array}{c}\text { Mean value } \\
\mu /\left(^{\circ}\right)\end{array}$ & $\begin{array}{c}\text { Standard } \\
\text { deviation } \\
\sigma /\left(^{\circ}\right)\end{array}$ & $\begin{array}{c}3 \sigma \\
\text { confidence } \\
\text { interval } /\left(^{\circ}\right)\end{array}$ & $\begin{array}{c}\text { Flight path } \\
\text { angle } \theta_{B} /\left(^{\circ}\right)\end{array}$ & $\begin{array}{c}\text { Yaw angle } \\
\psi_{B} /\left(^{\circ}\right)\end{array}$ & $\begin{array}{c}\text { Position } \\
\text { coordinate } /(\mathrm{m})\end{array}$ \\
\hline 1210 & 2.58 & 1.3 & $(0,6.48)$ & -30 & 0 & $(7291,687,0)$ \\
\hline
\end{tabular}

TABLE 4: View angle distribution results (moving target).

\begin{tabular}{|c|c|c|c|c|c|c|}
\hline $\begin{array}{l}\text { Distance to the } \\
\text { target } / \mathrm{m}\end{array}$ & $\begin{array}{c}\text { Mean value } \\
\mu /\left(^{\circ}\right)\end{array}$ & $\begin{array}{c}\text { Standard } \\
\text { deviation } \\
\sigma /\left(^{\circ}\right)\end{array}$ & $\begin{array}{l}3 \sigma \text { confidence } \\
\text { interval } /\left(^{\circ}\right)\end{array}$ & $\begin{array}{l}\text { Flight path } \\
\text { angle } \theta_{B} /\left(^{\circ}\right)\end{array}$ & $\begin{array}{l}\text { Yaw angle } \\
\psi_{B} /\left(^{\circ}\right)\end{array}$ & $\begin{array}{c}\text { Requirement (smaller } \\
\text { than } 10^{\circ} \text { ) }\end{array}$ \\
\hline 3000 & 4.3 & 1.1 & $(1,7.6)$ & -34.3 & -0.014 & $\mathrm{Y}$ \\
\hline 2750 & 2.7 & 1.2 & $(0,6.3)$ & -36.7 & -0.004 & $\mathrm{Y}$ \\
\hline 2250 & 1.6 & 0.9 & $(0,4.3)$ & -41.7 & 0.008 & $\mathrm{Y}$ \\
\hline 2000 & 2.9 & 1.3 & $(0,6.8)$ & -43.8 & 0.01 & $\mathrm{Y}$ \\
\hline 1500 & 6.7 & 1.8 & $(1.3,12.1)$ & -47.7 & 0.04 & $\mathrm{~N}$ \\
\hline 1250 & 9.1 & 2.3 & $(2.2,16)$ & -49.5 & 0.04 & $\mathrm{~N}$ \\
\hline 1000 & 12.2 & 2.5 & $(4.7,19.7)$ & -51.2 & -0.05 & $\mathrm{~N}$ \\
\hline
\end{tabular}




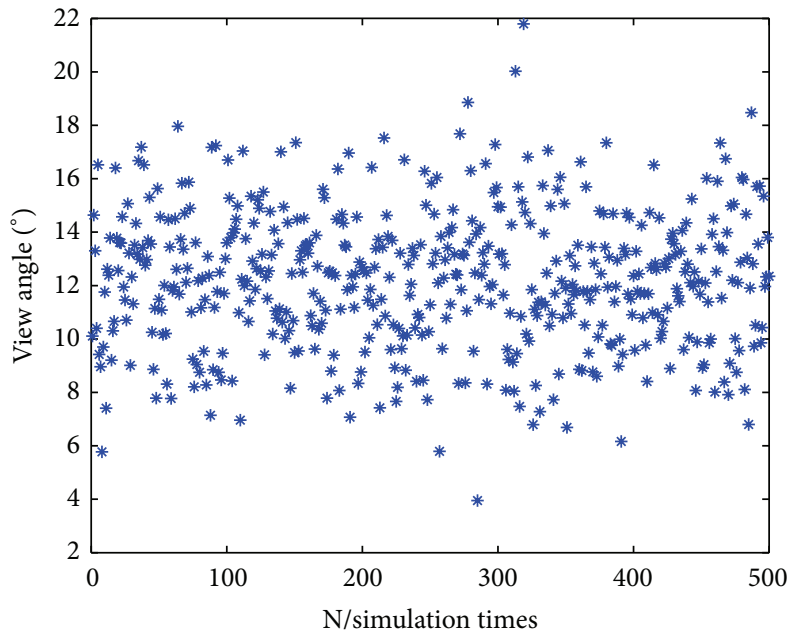

(a) Distance to the target $1000 \mathrm{~m}$

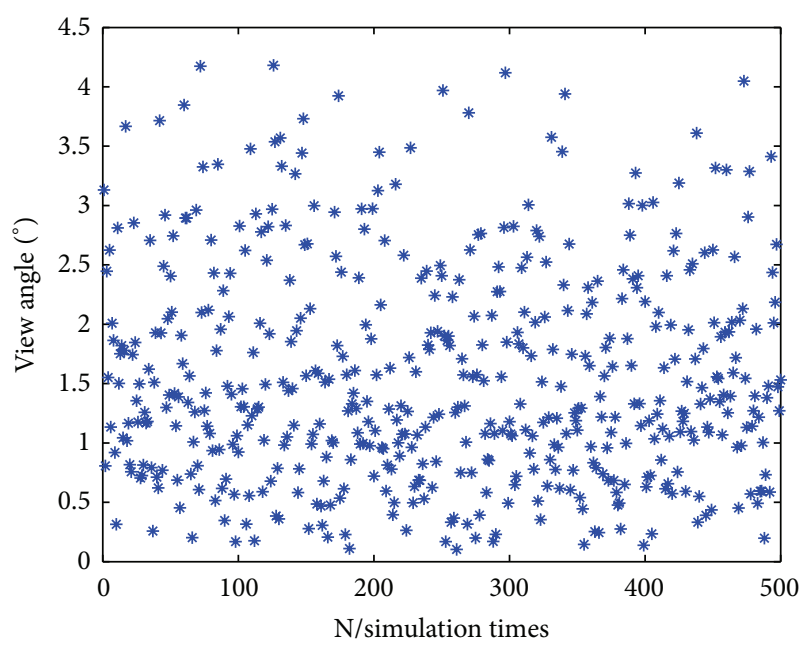

(c) Distance to the target $2250 \mathrm{~m}$

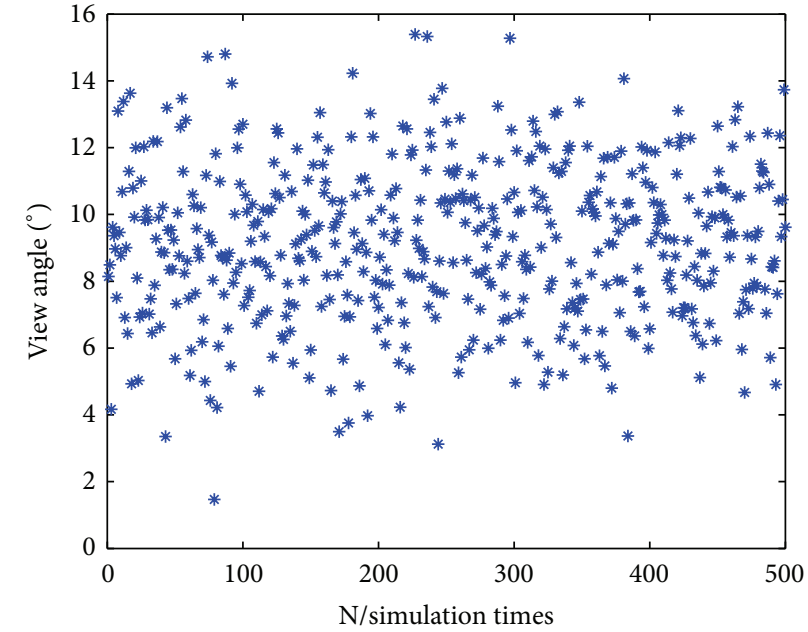

(b) Distance to the target $1250 \mathrm{~m}$

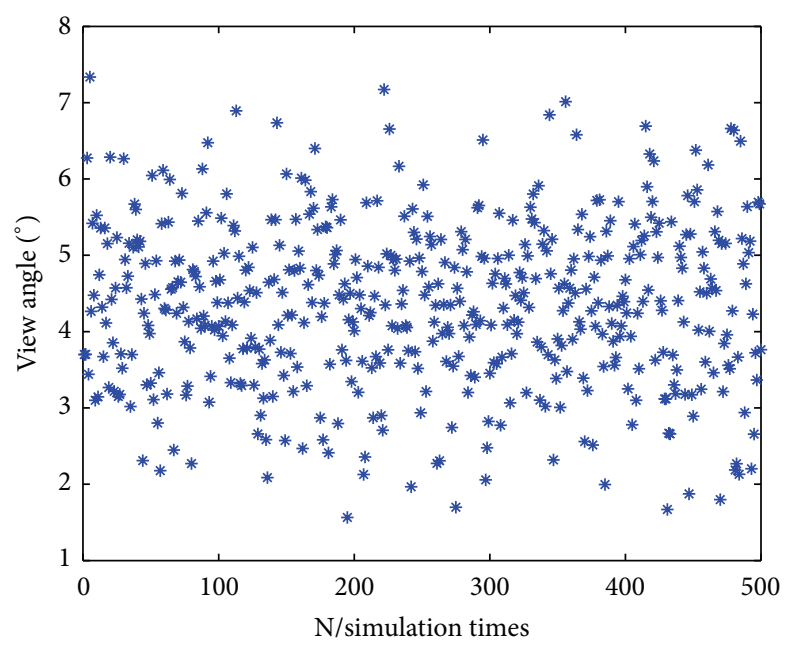

(d) Distance to the target $3000 \mathrm{~m}$

FIGURE 16: The distribution of view angle.

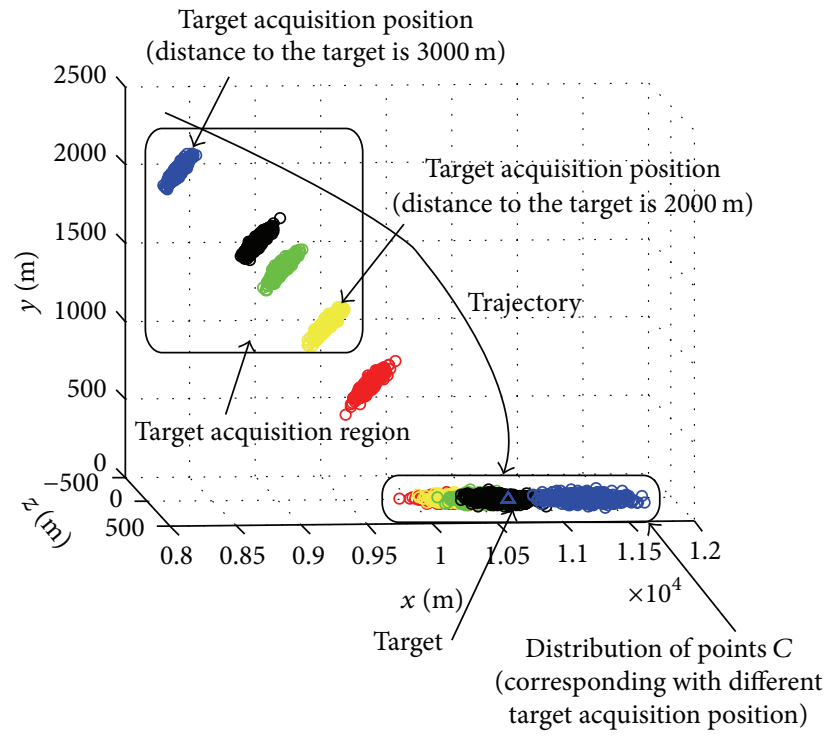

FIGURE 17: Target acquisition region. 


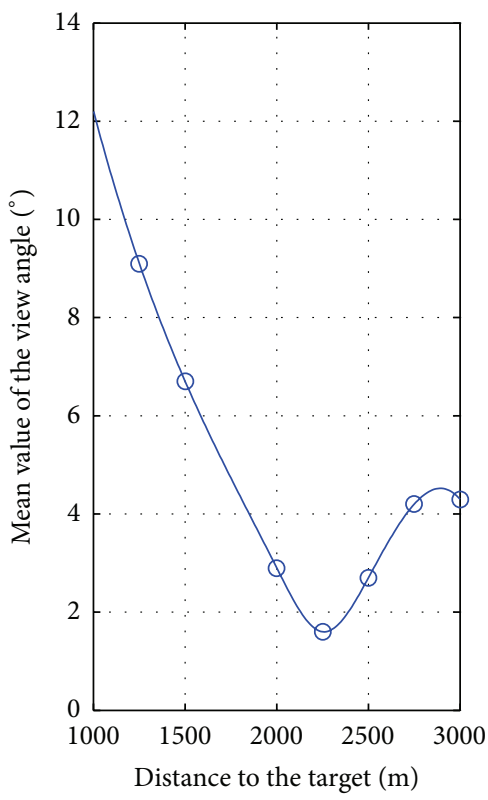

(a)

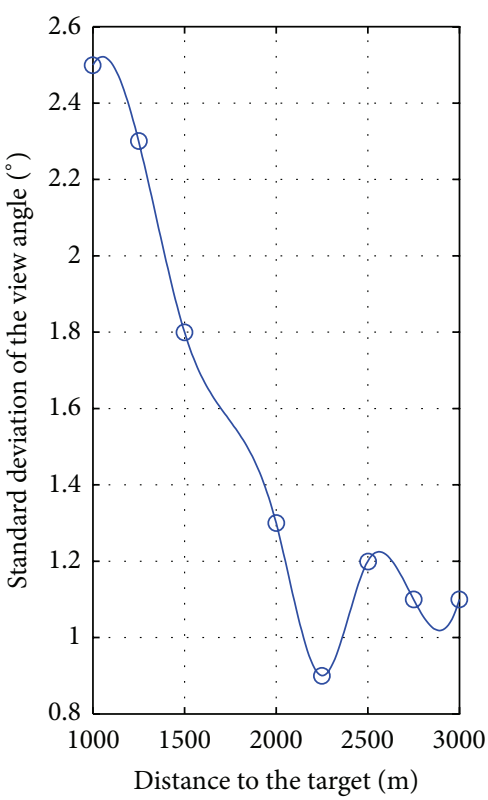

(b)

FIGURE 18: Cubic spline interpolation curve results (moving target).

TABle 5: The end point of midcourse guidance.

\begin{tabular}{lcccccc}
\hline $\begin{array}{l}\text { Distance from } \\
\text { the target } / \mathrm{m}\end{array}$ & $\begin{array}{c}\text { Mean value } \\
\mu /\left(^{\circ}\right)\end{array}$ & $\begin{array}{c}\text { Standard } \\
\text { deviation } \\
\sigma /\left(^{\circ}\right)\end{array}$ & $\begin{array}{c}3 \sigma \text { confidence } \\
\text { interval } /\left(^{\circ}\right)\end{array}$ & $\begin{array}{c}\text { Flight path } \\
\text { angle } \theta_{B} /\left(^{\circ}\right)\end{array}$ & Yaw angle $\psi_{B} /\left(^{\circ}\right)$ & $\begin{array}{c}\text { Position } \\
\text { coordinate } /(\mathrm{m})\end{array}$ \\
\hline 2260 & 1.5 & 0.9 & $(0,4.2)$ & -41.6 & -0.26 & $(8921,1740,0)$ \\
\hline
\end{tabular}

TABLE 6: Conditions for the simulations (fixed target).

\begin{tabular}{lc}
\hline Parameter & Value \\
\hline $\begin{array}{l}\text { Missile midcourse navigation } \\
\text { initial position }\left(x_{0}, y_{0}, z_{0}\right) / \mathrm{m}\end{array}$ & $(1000,1000,0)$ \\
$\begin{array}{l}\text { Missile midcourse velocity } V_{m} \\
(\mathrm{~m} / \mathrm{s})\end{array}$ & 278 \\
$\begin{array}{l}\text { The end position of the } \\
\text { midcourse guidance }\left(x_{f}, y_{f},\right.\end{array}$ & $(7291,687,0)$ \\
$\left.z_{f}\right) / \mathrm{m}$ & $(8287,0,0)$ \\
Target position $\left(x_{t}, y_{t}, z_{t}\right) / \mathrm{m}$ & $\theta_{B}=-30, \psi_{B}=0$ \\
$\begin{array}{l}\text { Terminal angular constraint } \theta_{B}, \\
\psi_{B} /^{\circ}\end{array}$
\end{tabular}

position $x_{0}, y_{0}, z_{0}$ and attitude angle $\theta_{0}, \psi_{0}$ or presume the missile follows a predetermined trajectory in the initial flight phase.

\section{Conclusion}

In this paper, the influence of the random disturbance and the distribution of the target acquisition points in 3D space corresponding to impact points on the ground are considered to ensure a satisfactory target acquisition probability
TABLE 7: Conditions for the simulations (moving target).

\begin{tabular}{|c|c|}
\hline Parameter & Value \\
\hline $\begin{array}{l}\text { Missile midcourse navigation } \\
\text { initial position }\left(x_{0}, y_{0}, z_{0}\right) / \mathrm{m}\end{array}$ & $(3000,3500,-500)$ \\
\hline $\begin{array}{l}\text { Missile midcourse velocity } V_{m} \\
(\mathrm{~m} / \mathrm{s})\end{array}$ & 370 \\
\hline $\begin{array}{l}\text { The end position of the } \\
\text { midcourse guidance }\left(x_{f}, y_{f} \text {, }\right. \\
\left.z_{f}\right) / \mathrm{m}\end{array}$ & $(8921,1740,0)$ \\
\hline $\begin{array}{l}\text { Target initial position }\left(x_{t}, y_{t},\right. \\
\left.z_{t}\right) / \mathrm{m}\end{array}$ & $(10360,0,0)$ \\
\hline Target velocity $\left(V_{t x}, V_{t y}, V_{t z}\right), \mathrm{m} / \mathrm{s}$ & $(10,0,0)$ \\
\hline $\begin{array}{l}\text { Terminal angular constraint } \theta_{B} \text {, } \\
\psi_{B} /^{\circ}\end{array}$ & $\theta_{B}=-41.6, \psi_{B}=-0.26$ \\
\hline Terminal LOS angle rate $\dot{q}_{r}(\% / s)$ & 0.2 \\
\hline $\begin{array}{l}\text { Proportional coefficient of PNG, } \\
k\end{array}$ & $k=3$ \\
\hline
\end{tabular}

(3 $\sigma$ principle, $99.7 \%$ ). A new midcourse guidance law has been presented to intercept the ground target for typical tactical missile. Numerical simulations in 3D scenarios have been carried out to validate the effectiveness of the derived guidance law. Compared with the PNG and NSMG, newly 


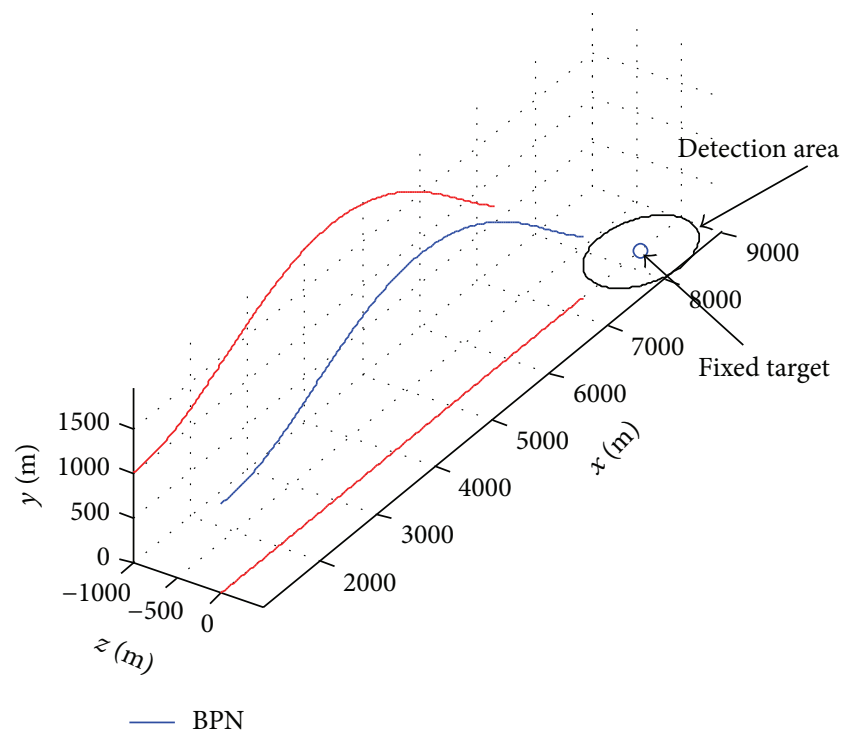

(a) Midcourse trajectory of BPN and the detection region (fixed target)

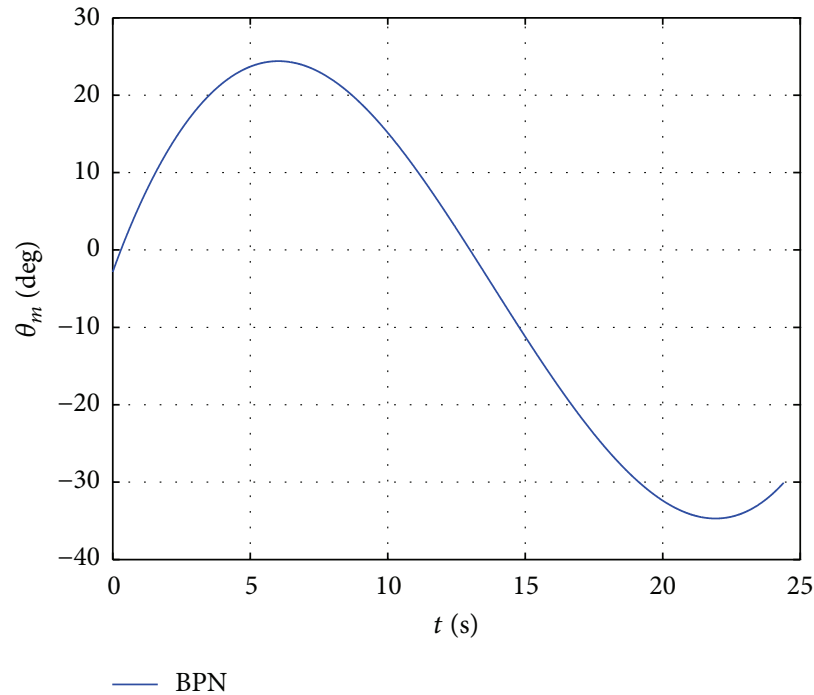

(b) Flight path angle

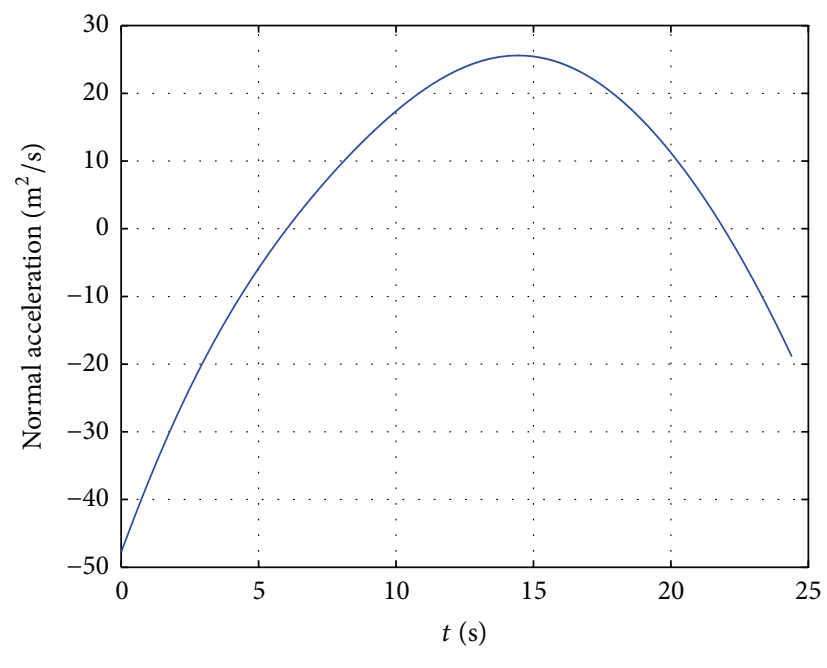

- BPN

(c) Normal acceleration

FIGURE 19: Midcourse simulation of BPN (fixed target).

TABLE 8: Conditions for the simulations (NSMG and BPN).

\begin{tabular}{lc}
\hline Parameter & Value \\
\hline Missile position $\left(x_{0}, y_{0}, z_{0}\right)(\mathrm{m})$ & $(3000,3500,-500)$ \\
Missile velocity $V_{m}(\mathrm{~m} / \mathrm{s})$ & 370 \\
The end position of the & $(8921,1740,0)$ \\
midcourse guidance $\left(x_{f}, y_{f}, z_{f}\right)$ & $(10360,0,0)$ \\
$(\mathrm{m})$ & 2 \\
Target position $\left(x_{t}, y_{t}, z_{t}\right) / \mathrm{m}$ & $\theta_{B}=-41.6, \psi_{B}=-0.26$ \\
Terminal LOS angle rate $\dot{q}_{r}\left({ }^{\circ} / \mathrm{s}\right)$ & \\
Terminal angular constraint $\theta_{B}$, & \\
$\psi_{B} l^{\circ}$ &
\end{tabular}

TABLE 9: Simulation of the different positions.

\begin{tabular}{lc}
\hline Missile initial positions $(x, y, z)$ & Value \\
\hline$\left(x_{1}, y_{1}, z_{1}\right) / \mathrm{m}$ & $(2000,3000,0)$ \\
$\left(x_{2}, y_{2}, z_{2}\right) / \mathrm{m}$ & $(1000,3000,-350)$ \\
$\left(x_{3}, y_{3}, z_{3}\right) / \mathrm{m}$ & $(2000,1000,-650)$ \\
$\left(x_{4}, y_{4}, z_{4}\right) / \mathrm{m}$ & $(2000,5000,500)$ \\
The end position of the & $(8921,1740,0)$ \\
midcourse guidance $\left(x_{f}, y_{f}\right.$, & \\
$\left.z_{f}\right) / \mathrm{m}$ & $\theta_{B}=-41.6, \psi_{B}=-0.26$ \\
Terminal angular constraint $\theta_{B}$, & 2 \\
$\psi_{B} l^{\circ}$ & \\
Terminal LOS angle rate $\dot{q}_{r}\left({ }^{\circ} / \mathrm{s}\right)$ & \\
\hline
\end{tabular}




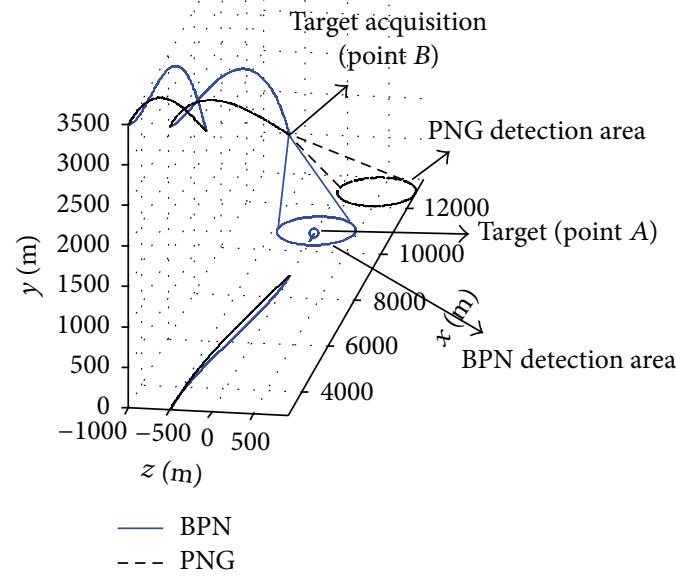

(a) Midcourse trajectory of BPN/PNG and their detection region (moving target)

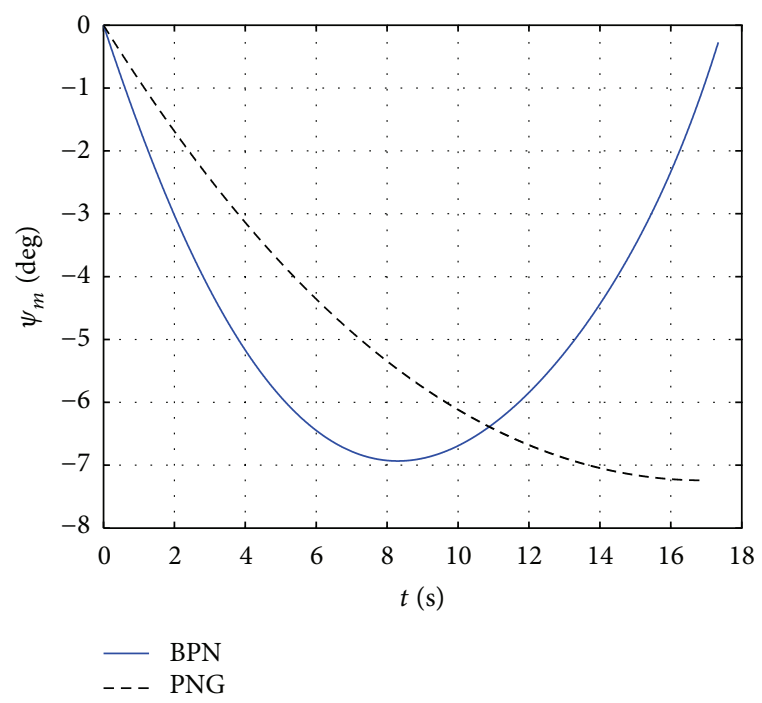

(c) Comparison of the flight path deflection angle

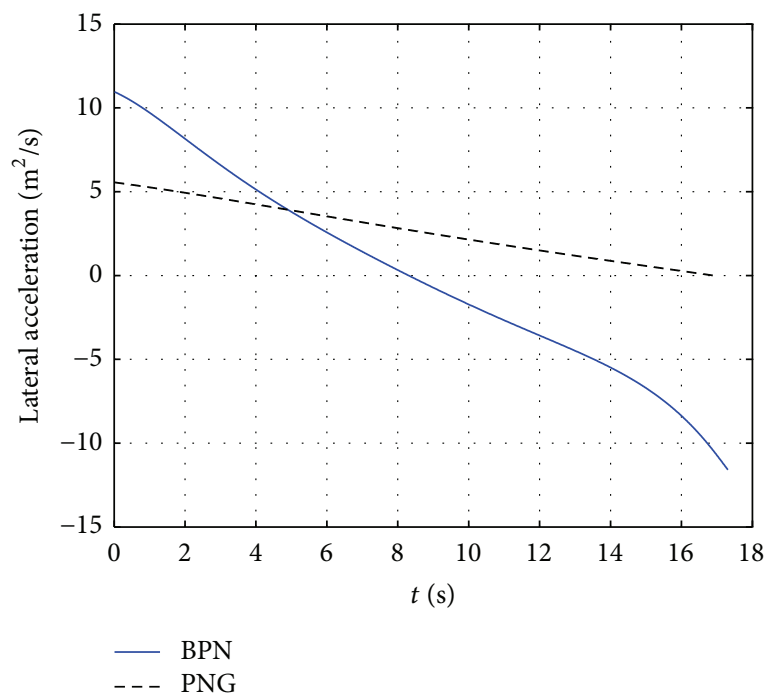

(e) Comparison of swerve plane acceleration

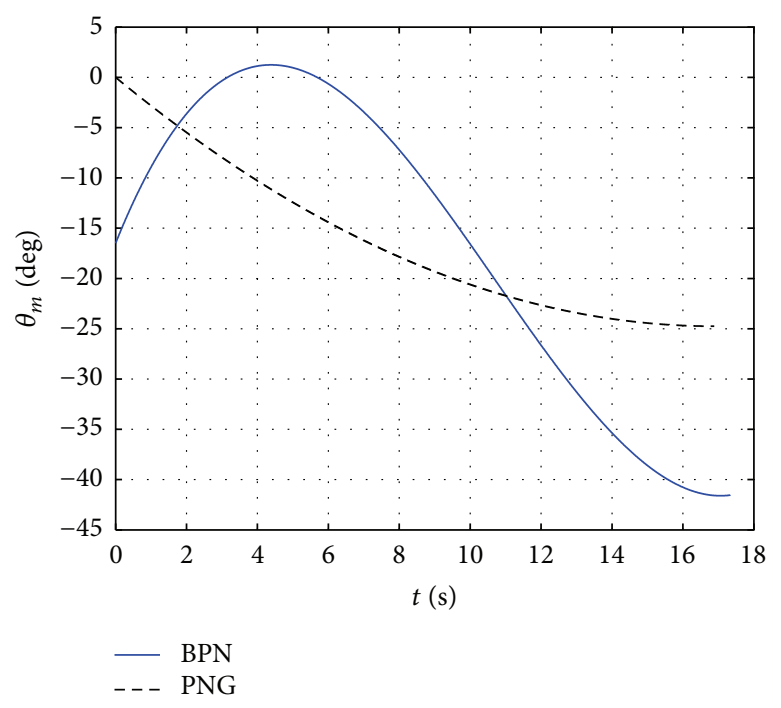

(b) Comparison of the flight path angle

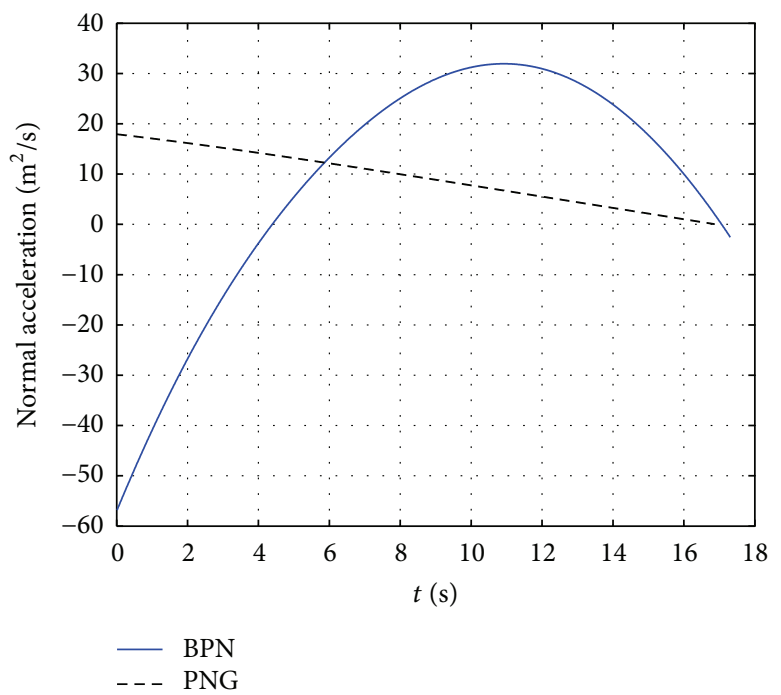

(d) Comparison of normal acceleration

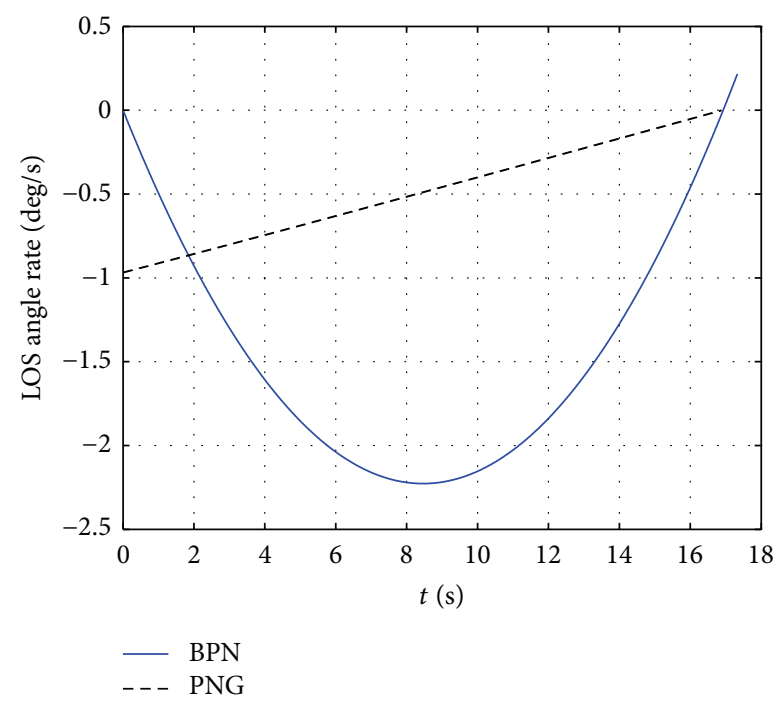

(f) Comparison of LOS angle rate

FIgURE 20: Comparison of PNG and BPN (moving target). 


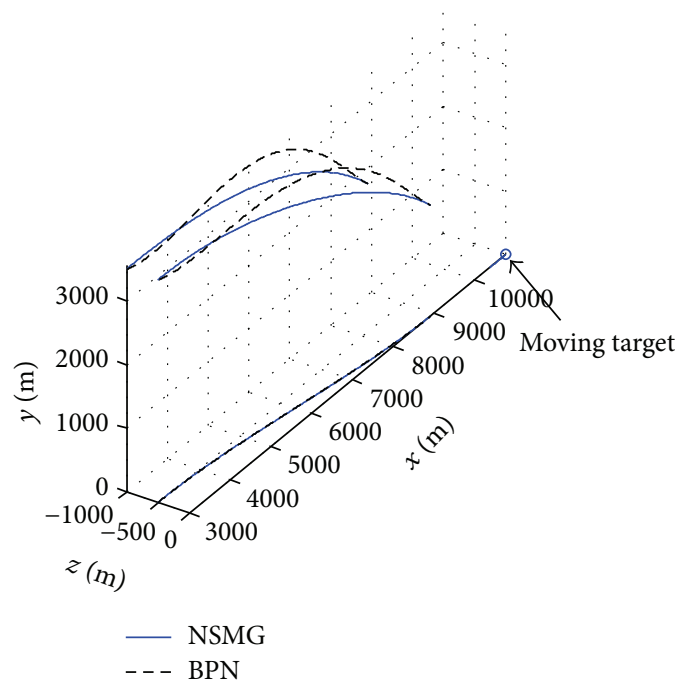

(a) Midcourse trajectory of NSMG/BPN and their detection region (moving target)

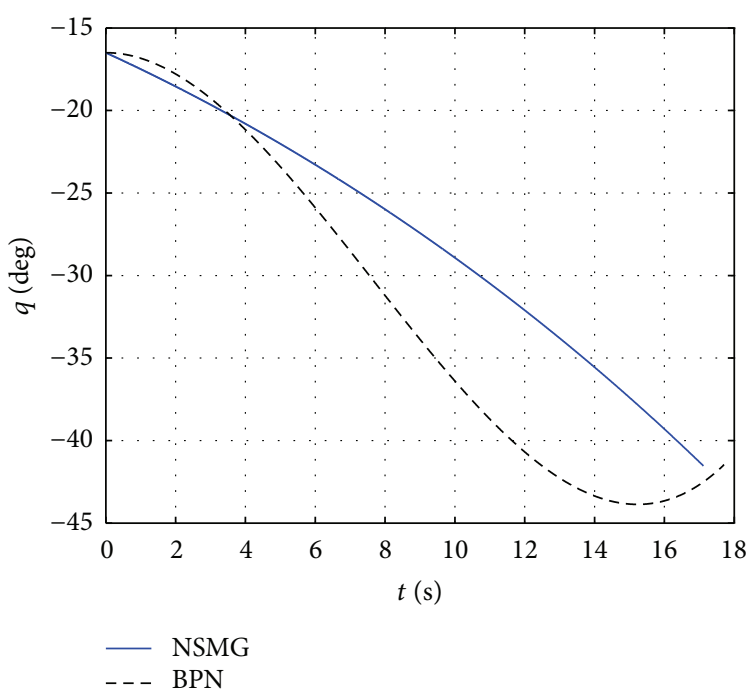

(c) Comparison of the LOS angle

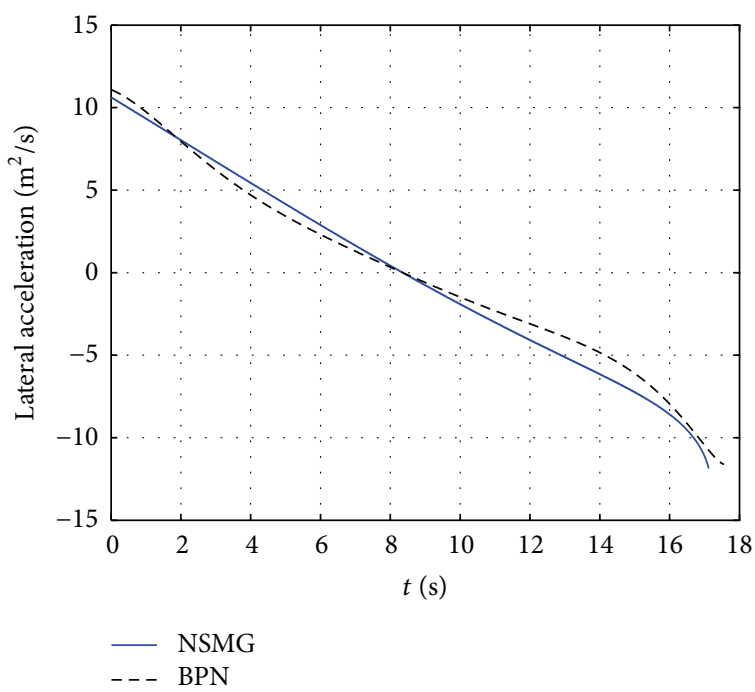

(e) Comparison of swerve plane acceleration

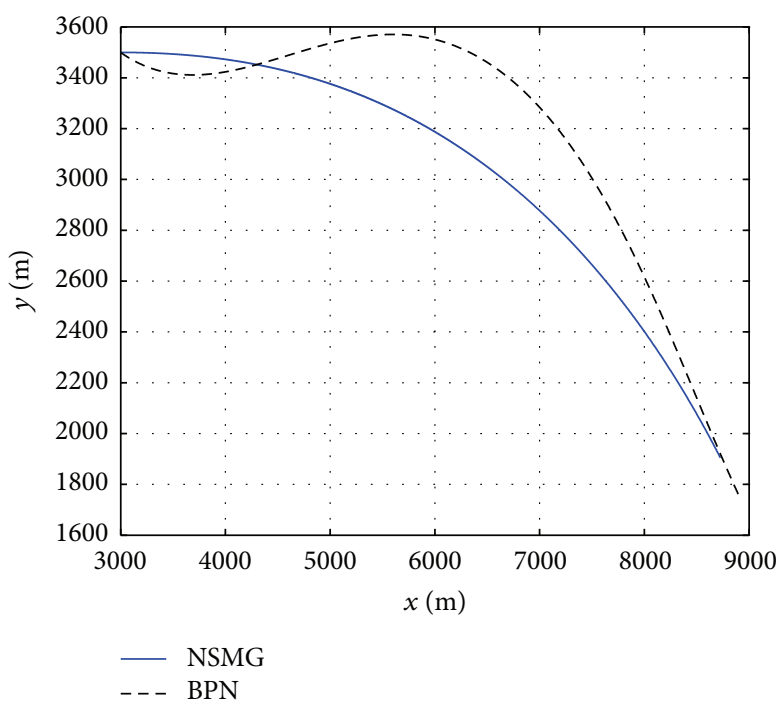

(b) Comparison of trajectory in pitching plane

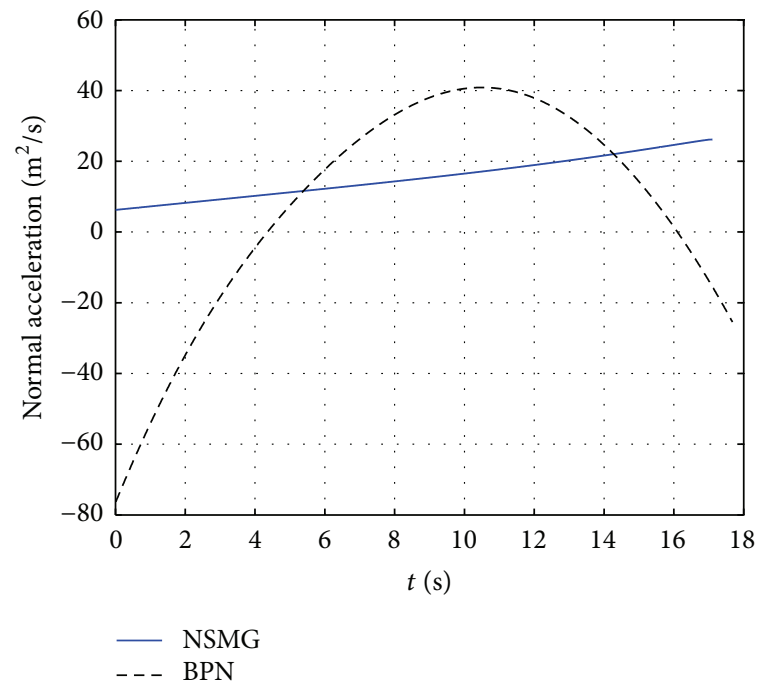

(d) Comparison of normal acceleration

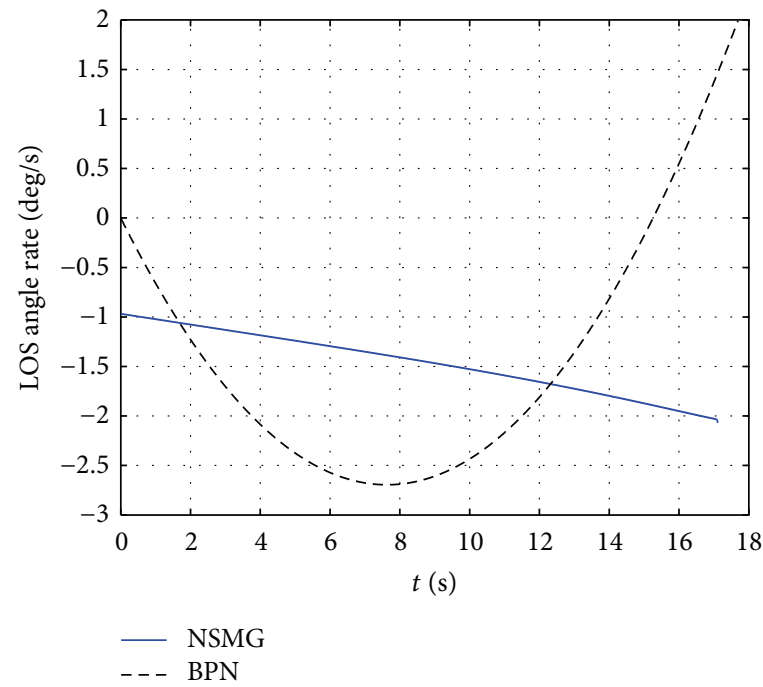

(f) Comparison of LOS angle rate

FIgure 21: Comparison of NSMG and BPN (moving target). 


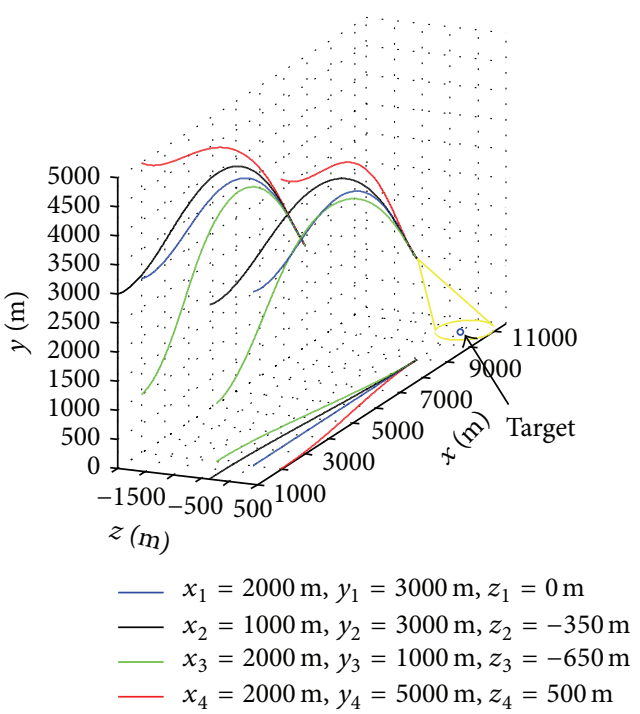

(a) Midcourse trajectory of BPN in different initial positions

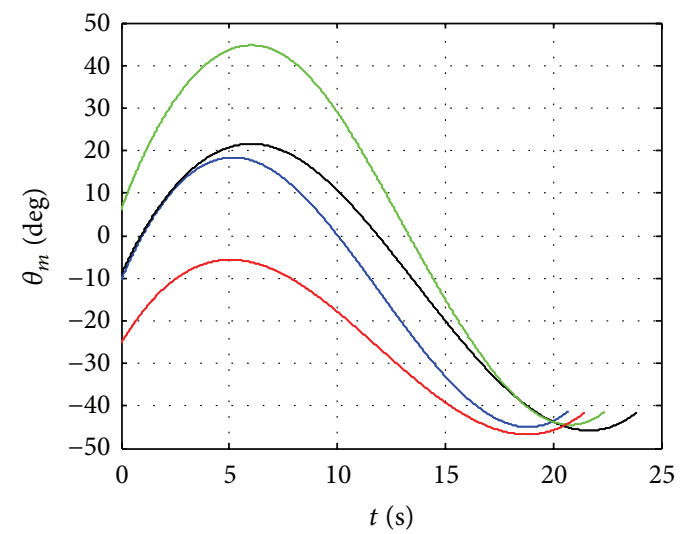

$-x_{2}=1000 \mathrm{~m}, y_{2}=3000 \mathrm{~m}, z_{2}=-350 \mathrm{~m}$

- $x_{3}=2000 \mathrm{~m}, y_{3}=1000 \mathrm{~m}, z_{3}=-650 \mathrm{~m}$

- $x_{4}=2000 \mathrm{~m}, y_{4}=5000 \mathrm{~m}, z_{4}=500 \mathrm{~m}$

(c) Comparison of the flight path angle

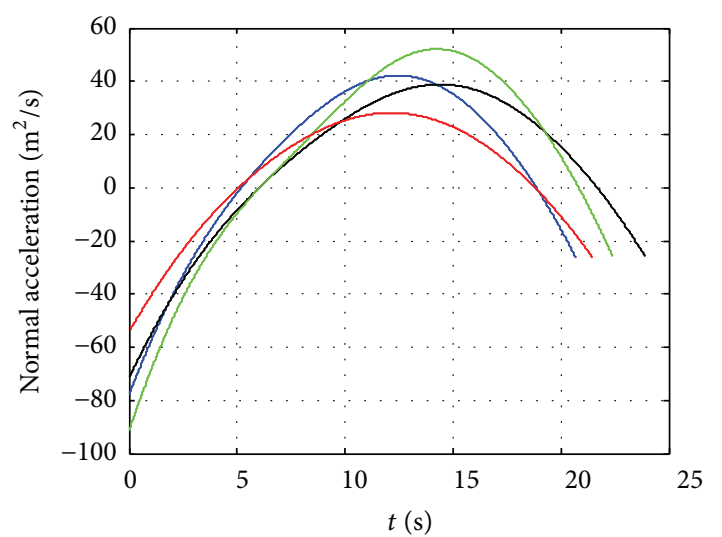

- $x_{1}=2000 \mathrm{~m}, y_{1}=3000 \mathrm{~m}, z_{1}=0 \mathrm{~m}$

$-x_{2}=1000 \mathrm{~m}, y_{2}=3000 \mathrm{~m}, z_{2}=-350 \mathrm{~m}$

- $x_{3}=2000 \mathrm{~m}, y_{3}=1000 \mathrm{~m}, z_{3}=-650 \mathrm{~m}$

- $x_{4}=2000 \mathrm{~m}, y_{4}=5000 \mathrm{~m}, z_{4}=500 \mathrm{~m}$

(e) Comparison of normal acceleration

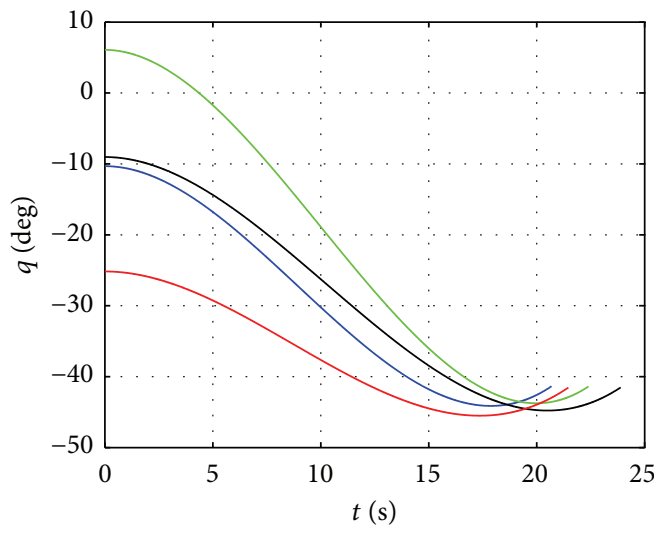

- $x_{1}=2000 \mathrm{~m}, y_{1}=3000 \mathrm{~m}, z_{1}=0 \mathrm{~m}$

- $x_{2}=1000 \mathrm{~m}, y_{2}=3000 \mathrm{~m}, z_{2}=-350 \mathrm{~m}$

- $x_{3}=2000 \mathrm{~m}, y_{3}=1000 \mathrm{~m}, z_{3}=-650 \mathrm{~m}$

— $x_{4}=2000 \mathrm{~m}, y_{4}=5000 \mathrm{~m}, z_{4}=500 \mathrm{~m}$

(b) Comparison of the LOS angle

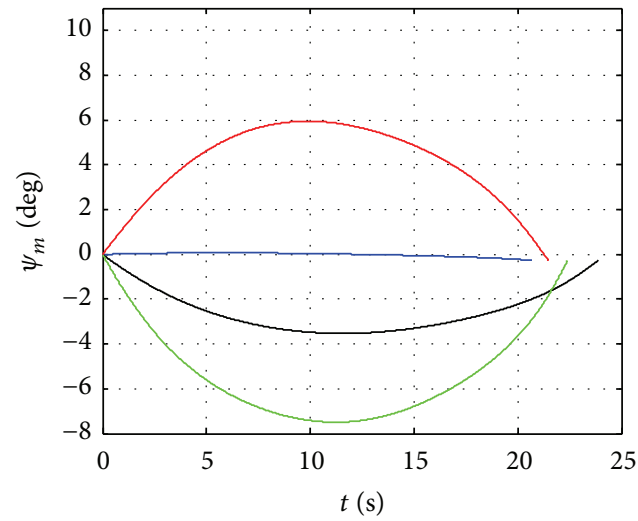

$$
\begin{aligned}
-x_{1} & =2000 \mathrm{~m}, y_{1}=3000 \mathrm{~m}, z_{1}=0 \mathrm{~m} \\
-x_{2} & =1000 \mathrm{~m}, y_{2}=3000 \mathrm{~m}, z_{2}=-350 \mathrm{~m} \\
x_{3} & =2000 \mathrm{~m}, y_{3}=1000 \mathrm{~m}, z_{3}=-650 \mathrm{~m} \\
-x_{4} & =2000 \mathrm{~m}, y_{4}=5000 \mathrm{~m}, z_{4}=500 \mathrm{~m}
\end{aligned}
$$

(d) Comparison of the flight path deflection angle

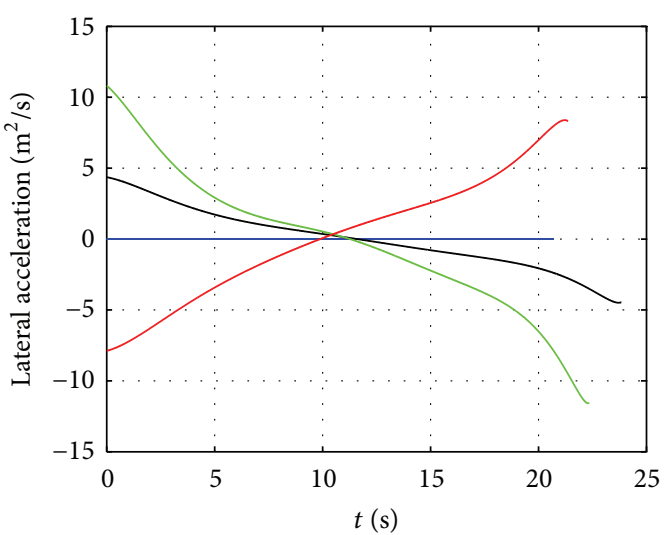

- $x_{1}=2000 \mathrm{~m}, y_{1}=3000 \mathrm{~m}, z_{1}=0 \mathrm{~m}$

- $x_{2}=1000 \mathrm{~m}, y_{2}=3000 \mathrm{~m}, z_{2}=-350 \mathrm{~m}$

- $x_{3}=2000 \mathrm{~m}, y_{3}=1000 \mathrm{~m}, z_{3}=-650 \mathrm{~m}$

- $x_{4}=2000 \mathrm{~m}, y_{4}=5000 \mathrm{~m}, z_{4}=500 \mathrm{~m}$

(f) Comparison of swerve plane acceleration

FIgURE 22: Continued. 


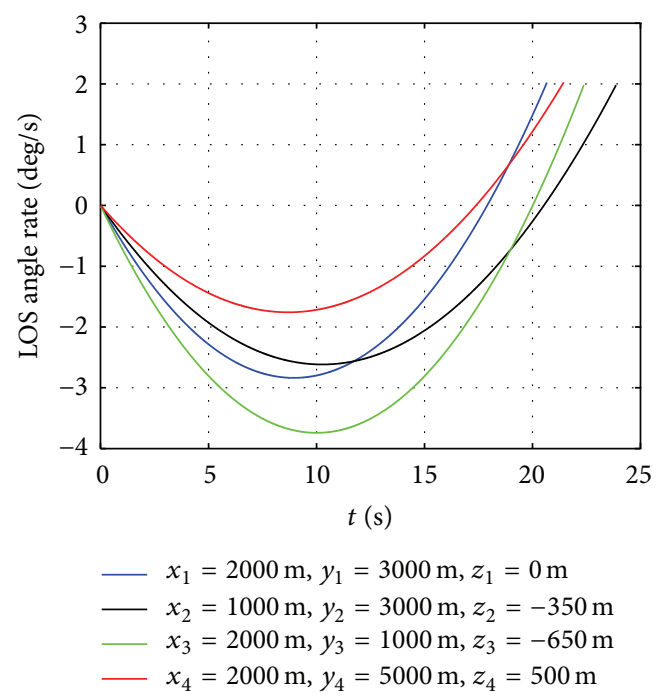

(g) Comparison of LOS angle rate

FIGURE 22: Comparison of BPN in different initial positions.

derived BPN can meet the zero midcourse miss distance, final angular constraint, and the LOS rate requirement. The designed guidance law enables the missile to possess the wide initial position and attitude angle envelope, supporting the missile with a better position as the starting point of the terminal phase.

\section{Competing Interests}

The authors declare that there are no competing interests regarding the publication of this paper.

\section{References}

[1] F. Fresconi, "Guidance and control of a projectile with reduced sensor and actuator requirements," Journal of Guidance, Control, and Dynamics, vol. 34, no. 6, pp. 1757-1766, 2011.

[2] R. Glebocki, R. Vogt, and M. Zugaj, "Smart mortar missile attitude detection based on the algorithm that takes advantage of artificial neural networks," in Proceedings of the AIAA Guidance Navigation, and Control Conference and Exhibit, AIAA Paper 2006-6703, Keystone, Colo, USA, August 2006.

[3] B. J. Guidos, "Deflection measurement accuracy in a coursecorrected 120-mm mortar spark range flight experiment," in Proceedings of the AIAA Atmospheric Flight Mechanics Conference and Exhibit, AIAA Paper 2004-5054, Providence, RI, USA, August 2004.

[4] P. N. Dwivedi, A. Bhattacharya, and R. Padhi, "Suboptimal midcourse guidance of interceptors for high-speed targets with alignment angle constraint," Journal of Guidance, Control, and Dynamics, vol. 34, no. 3, pp. 860-877, 2011.

[5] V. H. L. Cheng and N. K. Gupta, "Advanced midcourse guidance for air-to-air missiles," Journal of Guidance, Control, and Dynamics, vol. 9, no. 2, pp. 135-142, 1986.

[6] D. S. Naidu and A. J. Calise, "Singular perturbations and time scales in guidance and control of aerospace systems: a survey,"
Journal of Guidance, Control, and Dynamics, vol. 24, no. 6, pp. 1057-1078, 2001.

[7] P. Menon and M. Briggs, "A midcourse guidance law for air-toair missiles," in Proceedings of the AIAA Guidance, Navigation and Control Conference, AIAA Paper 1987-2509, August 1987.

[8] G. L. Slater and R. G. Stern, "Simplified midcourse guidance techniques," in Proceedings of the AIAA Stepping Stones to Mars Meeting, pp. 188-199, Baltimore, Md, USA, March 1966.

[9] C. Tournes, Y. Shtessel, D. Lianos, D. Foreman, and S. Jovanov, "Interceptor predictive mid-course higher order sliding mode guidance and control," in Proceedings of the AIAA Guidance Navigation, and Control Conference, AIAA Paper 2009-5896, August 2009.

[10] N. Indig, J. Z. Ben-Asher, and N. Farber, "Near-optimal spatial midcourse guidance law with an angular constraint," Journal of Guidance, Control, and Dynamics, vol. 37, no. 1, pp. 214-223, 2014.

[11] M. Kim and K. V. Grider, "Terminal guidance for impact attitude angle constrained flight trajectories," IEEE Transactions on Aerospace and Electronic Systems, vol. 9, no. 6, pp. 852-859, 1973.

[12] J. Bryson and Y. C. Ho, Applied Optimal Control, Hemisphere, Washington, DC, USA, 1975.

[13] C. K. Ryu and H. J. Cho, "Optimal guidance with terminal impact angle and control constraint," in Proceedings of the Korean Automatic Control Conference, pp. 601-606, Seoul, South Korea, October 1992.

[14] F. W. Nesline and P. Zarchan, "Line-of-sight reconstruction for faster homing guidance," Journal of Guidance, Control, and Dynamics, vol. 33, no. 1, pp. 269-275, 1985.

[15] M.-J. Tahk, C.-K. Ryoo, and H. Cho, "Recursive time-to-go estimation for homing guidance missiles," IEEE Transactions on Aerospace and Electronic Systems, vol. 38, no. 1, pp. 13-24, 2002.

[16] B. S. Kim, J. G. Lee, and H. S. Han, "Biased PNG law for impact with angular constraint," IEEE Transactions on Aerospace and Electronic Systems, vol. 34, no. 1, pp. 277-288, 1998. 
[17] C.-K. Ryoo, H. Cho, and M.-J. Tahk, "Optimal guidance laws with terminal impact angle constraint," Journal of Guidance, Control, and Dynamics, vol. 28, no. 4, pp. 724-732, 2005.

[18] R. L. Burden and J. D. Faires, Numerical Analysis, Brooks-Cole, Boston, Mass, USA, 9th edition, 2010.

[19] S. R. Kumar, S. Rao, and D. Ghose, "Sliding-mode guidance and control for all-aspect interceptors with terminal angle constraints," Journal of Guidance, Control, and Dynamics, vol. 35, no. 4, pp. 1230-1246, 2012.

[20] P. Zarchan, Tactical and Strategic Missile Guidance, AIAA, Washington, DC, USA, 5th edition, 2007.

[21] S. J. Tang, J. Guo, X. Li et al., Introduction to Flight Vehicle Systems, National Defense Industry Press, Beijing, China, 2012. 


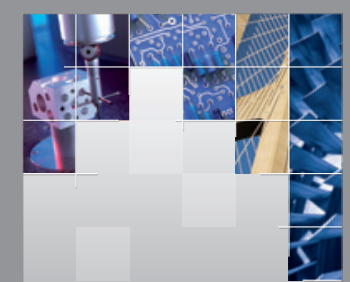

\section{Enfincering}
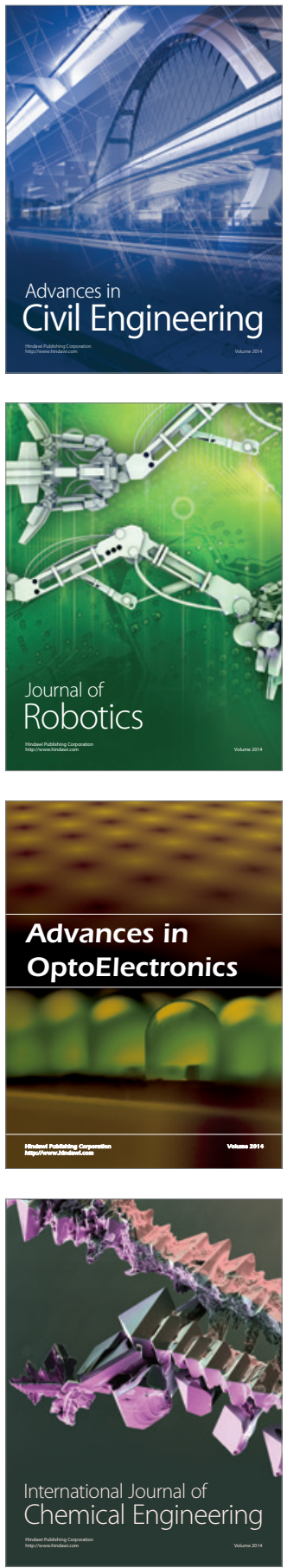

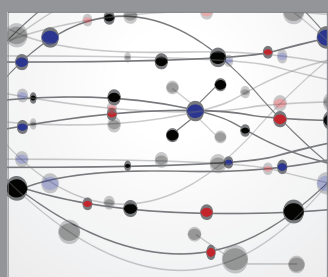

The Scientific World Journal

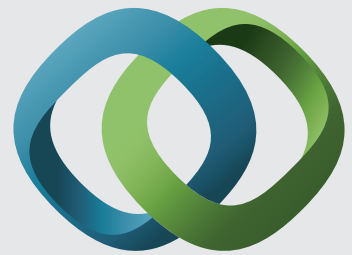

\section{Hindawi}

Submit your manuscripts at

http://www.hindawi.com
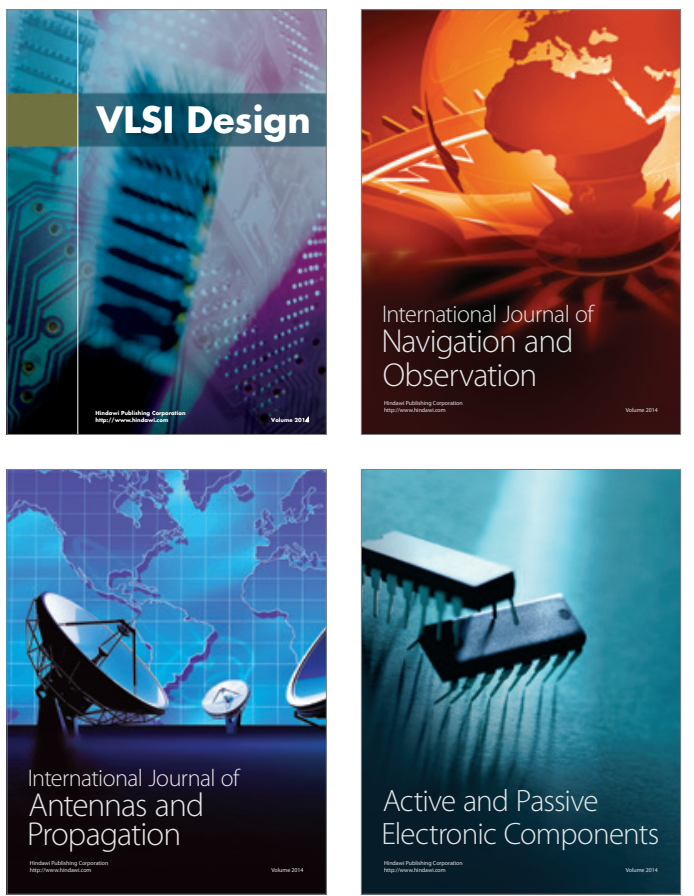
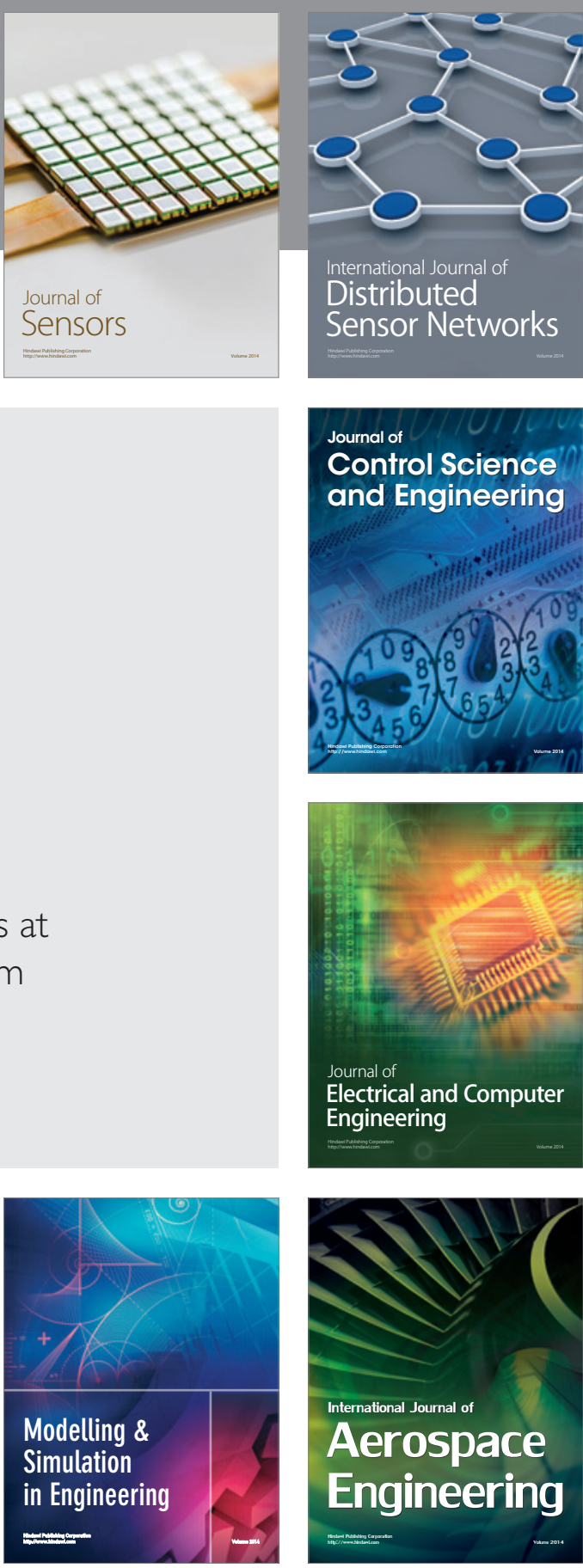

International Journal of

Distributed

Sensor Networks

Journal of

Control Science

and Engineering
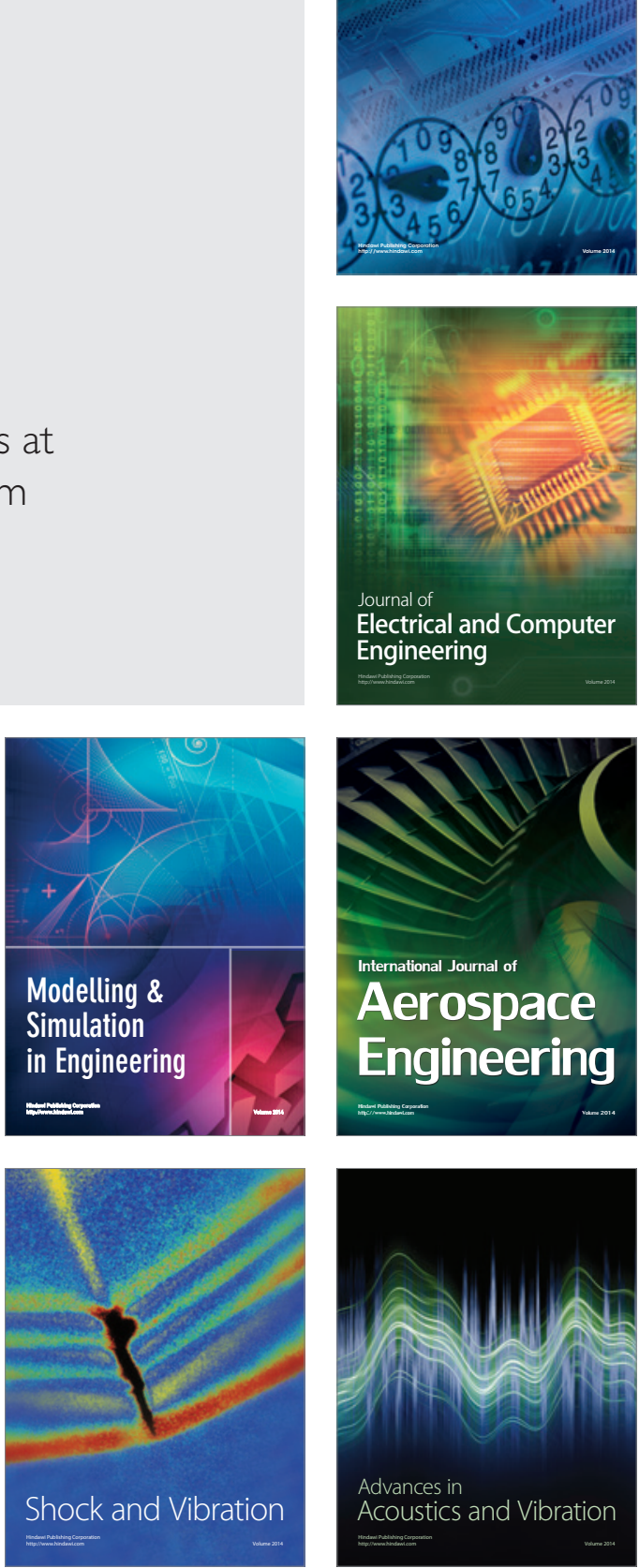